ORIGINAL ARTICLE

\title{
Antenatal dexamethasone exposure differentially affects distinct cortical neural progenitor cells and triggers long-term changes in murine cerebral architecture and behavior
}

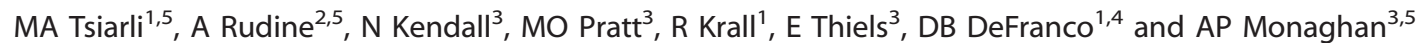

\begin{abstract}
Antenatal administration of synthetic glucocorticoids (sGC) is the standard of care for women at risk for preterm labor before 34 gestational weeks. Despite their widespread use, the type of sGC used and their dose or the dosing regimens are not standardized in the United States of America or worldwide. Several studies have identified neural deficits and the increased risk for cognitive and psychiatric disease later in life for children administered sGC prenatally. However, the precise molecular and cellular targets of GC action in the developing brain remain largely undefined. In this study, we demonstrate that a single dose of glucocorticoid during mid-gestation in mice leads to enhanced proliferation in select cerebral cortical neural stem/progenitor cell populations. These alterations are mediated by dose-dependent changes in the expression of cell cycle inhibitors and in genes that promote cell cycle re-entry. This leads to changes in neuronal number and density in the cerebral cortex at birth, coupled to long-term alterations in neurite complexity in the prefrontal cortex and hippocampus in adolescents, and changes in anxiety and depressive-like behaviors in adults.
\end{abstract}

Translational Psychiatry (2017) 7, e1153; doi:10.1038/tp.2017.65; published online 13 June 2017

\section{INTRODUCTION}

Synthetic glucocorticoids (sGCs) are widely used during pregnancy $(\sim 12 \%$ of US pregnancies) to reduce the risks associated with premature birth or congenital adrenal hyperplasia, and in the management of women with asthma or autoimmune disorders. ${ }^{1-3}$ Antenatal sGC administration mimics the endogenous fetal GC surge, stimulating organ maturation and significantly reducing the morbidity and mortality associated with respiratory distress syndrome, periventricular leukomalacia, intraventricular hemorrhage and necrotizing enterocolitis. ${ }^{3}$ However, it is becoming increasingly apparent that antenatal sGC administration can have detrimental neurological effects when it is administered during critical periods of brain development in human and other species (that is, gestation week 24-34 (GW ${ }^{4-12}$ ).

Currently, $25-30 \%$ of pregnant women treated with sGCs carry the pregnancy to term, ${ }^{13-15}$ leading to many children been exposed to sGCs without substantial benefit. Studies on term-born children exposed to sGCs in utero have provided convincing evidence for adverse neurological outcomes. ${ }^{13,14}$ Endogenous GC (that is, cortisol in humans) production begins between GW 30 and 32 in the developing infant (reviewed in Peffer et al. ${ }^{16}$ ); however, the majority of infants are exposed to sGC before 30 weeks, at a time when endogenous GCs are negligible. During this time, there is also minimal maternal contribution to fetal GCs because of efficient cortisol metabolism by placental 11ß-HSD2. ${ }^{17}$ Dexamethasone (DEX) and Betamethasone, potent sGCs resistant to $11 \beta-H S D 2$, are recommended for use in preterm labor between GW 24 and 34. It is during this critical period of gestation that brain development occurs rapidly, primarily in the cerebral cortex, with expansion of the cortical surface and elaboration of sulci and gyri. ${ }^{18}$

The glucocorticoid receptor (GR) protein is expressed in the human fetal brain during critical periods of neuroplasticity and development of neural and astroglial cells. ${ }^{19}$ We have previously shown that in mice GR exhibits a dynamic expression pattern in neural stem cells, progenitor cells and neurons at equivalent embryonic ages, well before endogenous murine hormone production begins. ${ }^{20}$ Accumulating evidence from both animal and clinical studies indicates that exposure to sGCs during the fetal or embryonic period may result in adverse neurological consequences that can be permanent and may manifest postnatally as cognitive, behavioral and affective problems. ${ }^{6,21-23}$ However, these studies have produced conflicting results, primarily because of differences in the timing of sGC administration and birth, concentration, dosing regiments and particular formulation of sGCs used and in the age at birth.

Whereas several studies have identified anatomical and behavioral changes after prenatal sGC exposure, few studies have identified the cellular and molecular targets in the developing brain. In this study, we sought to identify the immediate cellular and molecular targets of a single dose of sGC in the developing cerebral cortex in vivo and determine the long-term consequences of an adult brain architecture and behavior. Collectively, our results indicate that even a single dose of sGC during midneurogenesis can alter neural stem and progenitor cells (NSPC)

\footnotetext{
${ }^{1}$ Department of Neuroscience, University of Pittsburgh, Pittsburgh, PA, USA; ${ }^{2}$ Division of Newborn Medicine, Department of Pediatrics, University of Pittsburgh, Pittsburgh, PA, USA; ${ }^{3}$ Department of Neurobiology, School of Medicine, University of Pittsburgh, Pittsburgh, PA, USA; ${ }^{4}$ Department of Pharmacology and Chemical Biology, University of

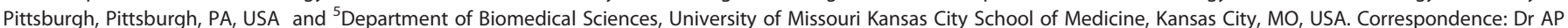
Monaghan, Department of Biomedical Sciences, University of Missouri Kansas City School of Medicine, 2411 Holmes Street, Kansas City, MO 64108, USA.

E-mail: (Nicholsap@umkc.edu)

${ }^{5}$ Joint first authors.

Received 12 August 2016; revised 9 February 2017; accepted 13 February 2017
} 
proliferation and lead to long-term changes in the cerebral cortical cytoarchitecture and adult behavior.

\section{MATERIALS AND METHODS}

Animals

Timed-pregnant CD-1 and C57BI/6 mice (age 8-12 weeks) were purchased from Charles River Laboratories (Raleigh, NC, USA), housed individually and received chow and water ad libitum. The day of vaginal plug was designated as E0.5. The Institutional Animal Care and Use Committee at the University of Pittsburgh approved animal protocols and procedures, and adheres to the National Institutes of Health guidelines. The University of Pittsburgh is an Association for Assessment and Accreditation for Laboratory Animal Care-approved site.

Embryonic tissue preparation and processing. Embryos were fixed in $4 \%$ paraformaldehyde (PFA; $\mathrm{pH} 7.4$ ) and processed through increasing sucrose gradients prior to cryosectioning. Subsequently, brains were embedded in Tissue-Tek Optimal Cutting Temperature compound (EMS, Hatfield, PA, USA) and sectioned at $20 \mu \mathrm{m}$. For paraffin sections, embryos were fixed overnight at $4^{\circ} \mathrm{C}$ in fresh "Sears" solution (30\% formalin; $10 \%$ glacial acetic acid; $60 \%$ pure ethanol), processed for paraffin embedding, and sectioned at $10 \mu \mathrm{m}$. A minimum of 4-6 animals was used for each experimental condition. For cortical measurements, sections were imaged on a Nikon fluorescent microscope, photographed with a Photometrics CoolSNAP digital camera and visualized with the NIS elements software (Nikon). Surface area and depth measurements were generated in NIS elements software using arbitrary units (AU) as defined by the measurement tool. For postnatal tissue, animals were perfused transcardially with phosphate buffered saline (PBS) followed by $4 \%$ PFA. Brains were isolated and processed through a sucrose gradient, frozen and sectioned at $50 \mu \mathrm{m}$.

Immunohistochemistry. Immunohistochemistry for cell markers was performed as described previously. ${ }^{19,25}$ Briefly, cryosections were dried for $30 \mathrm{~min}$ at $46^{\circ} \mathrm{C}$ and then washed with $0.1 \%$ Triton X-PBS (PBST). Paraffin sections were warmed at $56^{\circ} \mathrm{C}$ and then de-paraffinized and rehydrated through a series of xylene and decreasing concentrations of ethanol $(100 \%, 95 \%, 70 \%)$, rinsed with water and washed with PBST. Antigen retrieval was performed by microwaving in sodium citrate buffer $(10 \mathrm{mM}$ $\mathrm{pH}$ 6.0). Sections were then rinsed and blocked with $10 \%$ heat-inactivated normal goat serum (HINGS, Jackson ImmunoResearch, West Grove, PA, USA), for $1 \mathrm{~h}$ at room temperature, followed by $1-3$ overnight incubations at $4^{\circ} \mathrm{C}$ with the primary antibody. Sections were washed in PBST and incubated for $1 \mathrm{~h}$ in the secondary antibodies at room temperature, rinsed and counterstained with 4,6-diamidino-2-phenylindole. The primary and secondary antibodies used are described in Supplemental Table 1. Terminal deoxynucleotidyl transferase dUTP nick-end labeling (TUNEL) staining was performed using the Fluorescein In Situ Cell Death Detection Kit (Roche) on frozen brain sections, following the manufacturer's instructions. Fluorescent images were visualized with an Olympus Fluoview 1000 confocal microscope (single optical sections $2.5 \mu \mathrm{m}$ thickness) or a on a Nikon fluorescent microscope, photographed with a Photometrics CoolSNAP digital camera and visualized with the NIS elements software (Nikon). Images were assembled in Photoshop CS5.

$D E X$ administration. For in vitro cultures, primary neural stem cell cultures at P3 were incubated with $10^{-7} \mathrm{M}$ or $10^{-9} \mathrm{M}$ Dex or vehicle for $4 \mathrm{~h}$, RNA was extracted for RT-PCR. ${ }^{26,27}$ For in vivo assays, timed-pregnant mice at E14.5 were intraperitonealy (IP) administered a single dose of DEX $(0.4 \mathrm{mg}$ $\mathrm{kg}^{-1}$ ) or vehicle. Embryos were collected by cesarean section $6 \mathrm{~h}$ later. Six hours exposure to Dex was chosen instead of the $4 \mathrm{~h}$ used for in vitro assays to allow penetration of Dex into MNSC in the more complex environment in the developing brain. The cerebral cortex was dissected and RNA isolated using Trizol (Thermo Fisher) CDNA was synthesized using IScript (Thermo Fisher) and quantitative PCR performed using Sybrgreen as described (Thermo Fisher). Samples $(N=4)$ were prepared in triplicate and compared by Student's $t$-Test. Real-time PCR primer sequences are provided in the supplemental data (Table 2). For in vivo histological studies, a single dose of DEX $\left(0.4 \mathrm{mg} \mathrm{kg}^{-1}\right)$ or vehicle and 5-bromo-2'-deoxyuridine (BrdU, $50 \mathrm{\mu g} \mathrm{g}^{-1}$ ) was administered intraperitoneally to pregnant females at E14.5 between 10:00-11:00 am. Embryos were collected by cesarean section either $24,72 \mathrm{~h}$ or at postnatal day 10 (P10) after DEX injection between 10-11:00 am.
In vivo proliferation quantification. Pregnant animals were injected with a single dose of BrdU and DEX or vehicle on E14.5; embryos were collected $24 \mathrm{~h}$ later and processed for immunohistochemistry. Coronal sections of the somatosensory and motor cortex were stained with an anti-BrdU antibody and counterstained with DAPI. Pax6 and Tbr2 staining was used to identify the radial glial cells (RGC's) and intermediate progenitor cells (IPC's) populations, respectively. Fluorescent images were visualized with an Olympus Fluoview 1000 confocal microscope ( $2.5 \mu \mathrm{m}$ optical sections). Cell counts were performed by an observer blind to the treatment group, on stacked images in a $150 \mu \mathrm{m}$ horizontal window of the cortical wall. For E17.5 sections, the cortical wall was split into 10 equal bins from the pial to ventricular surface, and the total number of DAPI-positive cells and BrdUpositive counted. In addition, the subplate (SP) and layer VI marker, Tbr1, were used to identify the SP and layer VI from the intermediate zone.

Fluorescence-activated cell sorting analysis. The E15.5 dorsal cortex tissue was dissected in cold PBS following $24 \mathrm{~h}$ of DEX and BrdU exposure on E14.5. The tissue was dissociated in PBS, filtered through a $40 \mu \mathrm{m}$ filter, washed in PBS, and fixed in 70\% ethanol for 30-60 min at $4^{\circ} \mathrm{C}$. Cells were subsequently washed in ice-cold PBS, and antigen retrieval was performed by incubation with $2 \mathrm{~N} \mathrm{HCl}$ for $30 \mathrm{~min}$ at room temperature. Cells were washed with PBS, blocked with $10 \%$ HINGS and incubated with the BrdU antibody in $10 \%$ HINGS for $30 \mathrm{~min}$ at room temperature, pelleted, rinsed with PBS, incubated with anti-rat Alexa 647 (1:1000, Invitrogen) and counterstained with DAPI. Flow cytometry was performed at the University of Pittsburgh Immunology Flow Cytometry Core, using an LSRFortessa cytometer.

Neurosphere proliferation assays. The cerebral cortex was dissected from E14.5 embryos and neurosphere cultures established as described. ${ }^{28}$ At passage $3,1.4 \times 10^{4}$ cells were seeded in a 96-well plate. Twenty-four hours later, $10^{-9}, 10^{-8}$ or $10^{-7} \mathrm{M}$ Dex or vehicle was added and cells were grown for $25 \mathrm{~h}$. At $22 \mathrm{~h}$, Fluorometric Blue (Abcam ab102501) was added to $10 \%$ final concentration. Fluorescent intensity was measured $3 \mathrm{~h}$ later on a fluorescent plate reader according to the manufacturer's instructions (Abcam). Each proliferation assay was performed with eight biological replicates, with corresponding technical triplicates.

Microarray. Differential gene expression was examined using mouse cell cycle microarray plates as per the manufacturer's instructions (SABiosciences, PAMM-020-A). Raw values were normalized to housekeeping genes and $t$-tests from three independent experiments were carried out to identify genes with more than a 2.0 -fold increase or $50 \%$ decrease in expression with $P<0.05$ using SABiosciences software tools.

Golgi impregnation. Golgi-Cox impregnation was performed using procedures outlined in the FD Rapid Golgi Stain Kit (FD Neurotechnologies) with some modifications. Fresh P10 brains were rinsed in double distilled $\mathrm{H}_{2} \mathrm{O}$ and placed in 'Solution A/B' overnight. After 5 days, the solution was replaced with fresh $A / B$ and left undisturbed for 1-3 additional days. Brains were then incubated in Solution $C$ for 3 days, flash frozen with isopentane on dry ice, cryosectioned at $100 \mu \mathrm{m}$ and collected on gelatin-coated slides in solution C, and air-dried for $24 \mathrm{~h}$. Sections were rinsed in water and incubated in solution D/E for $10 \mathrm{~min}$ and counterstained with Nissl, mounted and imaged.

Golgi analysis. A minimum of 3 neurons per animal $(N \geq 5)$ was imaged for Sholl analysis. The anterior cingulate was identified (Bregma $+2.1 \mathrm{~mm}$ ) and individual pyramidal neurons were selected in layer V. The dorsal hippocampus was identified (Bregma $-1.4 \mathrm{~mm}$ ) and divided into CA1 and $C A 2 / 3$ anatomical areas. For all regions analyzed, care was taken to identify isolated pyramidal neurons in each region, with no/minimal overlap between branches of the neuron. Images were obtained at $20 \times$ for hippocampal neurons, and 10x for prefrontal cortex neurons for analysis in ImageJ $(\mathrm{NIH})$. Neuronal morphology of sections was analyzed with minor modifications as described in ref. 29. Cell soma and neurites were traced by hand, taking care that each branch point was traced independently using NeuronJ plug-in (NIH), by an experimenter blind to treatment group. The cell body and neurite tracings were saved and exported for measurement in NeuronJ, processed in Bonfire (Langhammer et al, Cytometry 2010, Rutgers), a software component of MatLab (The MathWorks) and analyzed in NeuronStudio (NeuronStudio Documentation CNIC, Mount Sinai School of Medicine). This Bonfire program was used to extract morphological data. Finally, all data were exported into Excel (Microsoft) and analyzed for 
statistical significance using Prism6 (GraphPad Software, La Jolla, CA, USA). Error bars represent standard error of the mean.

\section{Behavior experiments}

All mice were tested in the Rodent Behavior Analysis Core of the University of Pittsburgh Schools of Health Sciences between noon and 1900 h. All experiments and data analysis were recorded and analyzed by an observer blind to the treatment group. A single dose of DEX $(0.4 \mathrm{mg} / \mathrm{kg})$ or vehicle was administered intraperitoneally to time-pregnant C57BI/6 females at E14.5. Animals were monitored for the first 4 days after birth and then weekly. No significant difference in body weight, gross pup, adolescent, adult or maternal behavior was observed. At postnatal day 60 (P60) male animals were transferred to the behavior testing facility and allowed to acclimatize for 2 weeks. Prior to the start of behavioral testing, mice were handled twice daily for $1 \mathrm{~min}$, for 5 consecutive days. Mice were observed in a clean cage for $3 \mathrm{~min}$ to examine general physical characteristics (locomotion, grooming, feeding, response to sound) and behavior. Vision was informally tested using the visual placing task.

Open-field test. To evaluate exploratory activity, mice were placed into a test arena equipped with infrared light beams and sensors for a 15-min test period (arena size: $25.4 \mathrm{~cm}$ by $25.4 \mathrm{~cm}$, with infra-red beams spaced $1.5 \mathrm{~cm}$ apart; Coulbourn Instruments, Whitehall, PA, USA). The arena was housed in a sound-attenuating chamber. Data were collected using Tru Scan 2.0 software (Coulbourn Instruments). Measures analyzed included number of ambulatory bouts, total ambulatory time, total distance traveled, average ambulatory velocity, time spent in the center of the arena versus time spent outside the center, frequency of rearing (vertical plane entries), and frequency of 'stereotypic' (repetitive) movement.

Forced swim test. The Porsolt forced swim test was used to test behavioral despair. Mice were placed in a glass cylinder $(20 \mathrm{~cm}$ diameter) filled with water $\left(22.5-23^{\circ} \mathrm{C}\right)$ up to a height of $10 \mathrm{~cm}$ and recorded for $6 \mathrm{~min}$. Limelight software (Coulbourn Instruments) was used to video-track the mice for subsequent analysis of floating time. Percent time floating was independently scored by two individuals blind to the treatment group, with data reported for the last $4 \mathrm{~min}$ of the task. Floating was defined as immobility in the water, except for movements necessary for the animal to keep its head above water, as opposed to active swimming or attempts to escape.

Elevated plus maze. Mice were placed into one of the closed arms of an elevated plus maze, dimensions: 24 inches tall, arm length, $35.5 \mathrm{~cm} \times$ $5.0 \mathrm{~cm}$ per arm; center area, $5 \mathrm{~cm} \times 5 \mathrm{~cm}$, enclosed arm height, $16 \mathrm{~cm}$ ), and their activity was recorded for $10 \mathrm{~min}$. The behavior was video captured and videos analyzed offline. Two individuals independently scored parameters, blind to treatment group. The latency to enter an open arm, number of open arm entries, and time spent in the open arms was recorded by an observer blind to the treatment group.

\section{Quantification and statistical analysis}

For anatomical studies, all analyses were performed by an experimenter blind to the treatment group. All statistical data are presented as mean \pm s.d. or mean \pm s.e.m. depending on the analytical tools of the software used (identified in each figure). Data were tested for statistical significance by the two-tailed Student's $t$-test using the GraphPad Prism software 6 (GraphPad Software), at a significance level of 0.05, using an $n \geqslant 4-6$ per experimental condition. A power analysis was used to determine sample size using http://biomath.info/power/ttest.htm. For Golgi/Sholl analysis, a one-way analysis of variance was used to test for significance in treated versus control samples, with Tukey's post hoc analysis for further comparison.

For behavior experiments, all analyses were performed by an experimenter blind to the treatment group. Statistical analysis was performed using the SPSS 14.0 software (SPSS, Chicago, IL, USA). Data were compared between genotypes using unpaired $t$-tests or analysis of variance followed by Dunnett's post hoc analysis as indicated. All values are expressed as mean \pm s.e.m. Graphs were generated using GraphPad Prism 4 (GraphPad Software).

\section{RESULTS}

A single dose of DEX during mid-gestation impairs cerebral cortical development

In light of the finding that prenatal DEX administration is associated with neurological abnormalities in term-born children, and our previous findings that both continuous and transient exposure of primary mouse embryonic NSPC cultures to DEX limits proliferation, we investigated the in vivo consequences of a single dose of antenatal DEX on fetal brain development. On the basis of completed gestational age, the American College of Obstetrics and Gynecology recommends four intramuscular injections of a 6$\mathrm{mg}$ dose of DEX over a 2-day period to pregnant women at risk of premature delivery (23-34 GW), which would attain a peak blood concentration of $2.3 \times 10^{-7} \mathrm{M}$. As endogenous GC production begins at $30-32 \mathrm{GW}^{24}$ a significant number (30\% (ref. 15)) of termborn children are exposed to sGC during fetal development. We reasoned that it was most relevant in our mouse model to mimic the steroid-naive environment present up to $\sim 30$ gestational weeks in humans and, therefore, injected pregnant mice with a single $0.4 \mathrm{mg} \mathrm{kg}^{-1}$ dose of DEX (it approximates the minimal dose $\left(0.35 \mathrm{mg} \mathrm{kg}^{-1}\right)$ used clinically in humans) at E14.5 at least 2 days before fetal endogenous GC production begins. ${ }^{25}$ The short-term effects of DEX exposure on stem cell proliferation and differentiation and the long-term effects on neuronal morphology and animal behavior were examined.

At birth, one of the most frequent findings in children exposed to prenatal sGc is a decrease in head circumference and body weight. To determine whether, similar to human studies, antenatal DEX exposure in mice leads to a change in brain weight or size at birth, the brain-to-body weight ratio (BBWR) was compared between control and DEX-exposed mice $72 \mathrm{~h}$ after initial sGC exposure ( 0.5 days before birth). No difference in the brain or body weight or BBWR was observed in animals injected with PBS versus the vehicle control ethanol (EtOH) from two independent litters, which verifies that the concentration of the vehicle, ethanol, used in our studies does not exert a significant biological effect (Figure 1a, data from three litters pooled, $n_{\mathrm{PBS}}=8$ BBWR $0.086 \pm 0.006 \mathrm{~g}, n_{\mathrm{DEX}}=8$ BBWR $0.086 \pm 0.006 \mathrm{~g}$, $P=0.65)$. There was no significant difference in body weight in DEX-exposed animals compared to controls; however, the BBWR was reduced by $15 \%$ compared to the controls (Figure $1 \mathrm{~b}$, $n_{\text {control }}=24, n_{\text {DEX }}=18$, control BBWR $0.064 \pm 0.006 \mathrm{~g}$, DEX BBWR $0.056 \pm 0.005 \mathrm{~g}, P<0.001)$. This result suggests that a single antenatal exposure with DEX at E14.5 leads to an impairment in brain growth.

In humans, antenatal GC exposure is associated with a reduction in the cortical surface area and depth.,13 Cortical surface and depth are a reflection of cortical cytoarchitectural integrity. Therefore, to determine whether the reduction in brain weight was due to a decrease in the size of the cerebral cortex, cortical surface and cortical depth were compared in Nissl-stained coronal sections at E17.5, $72 \mathrm{~h}$ after DEX or vehicle exposure, as outlined previously. ${ }^{26,27}$ In DEX-treated animals, the cortical surface was reduced by $15 \%$ (mean \pm s.d., $n_{\text {control }}=5$; control: $763 \mathrm{AU} \pm 36, n_{\mathrm{DEX}}=6$; DEX: $\left.667 \mathrm{AU} \pm 18, P<0.001\right)$ and cortical thickness by $10 \%$ (control: $120 \mathrm{AU} \pm 3.8, \mathrm{DEX}: 105 \mathrm{AU} \pm 8.3$ and $P<0.01$; Figures $1 \mathrm{~b}-\mathrm{d}$ ).

\section{Antenatal DEX exposure promotes supernumerary neuron} production in deep and superficial cortical layers

In our animal model, DEX is administered during peak neurogenesis when cerebral cortical layers V-II are being specified. Specifically, at E14.5, neurogenesis in layer VI is almost complete, while layer $\mathrm{V}$ neurogenesis has just peaked. ${ }^{28}$ Production of layers IV-II occurs from E14.5 and is complete at birth (see Figure $2 \mathrm{f}$ for a schematic representation of cortical laminar neurogenesis). To determine whether the DEX-induced decrease in cortical growth 

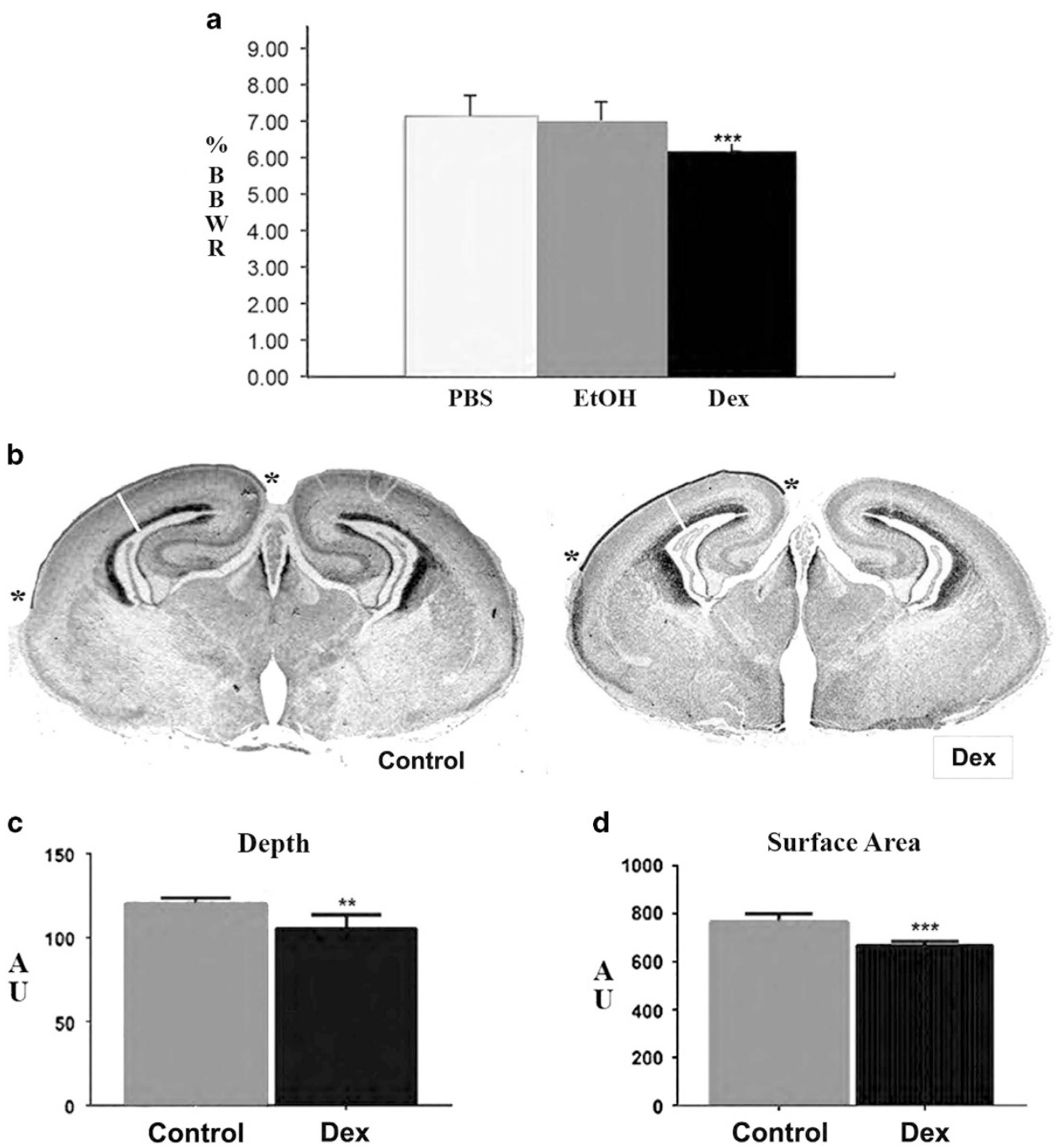

Figure 1. A single dexamethasone (DEX) course during mid-gestation impairs cortical development in the fetus (a). DEX administration at E14.5 leads to a decrease in the brain-to-body weight ratio (BBWR) just before birth compared to vehicle treatment at E14.5 (ethanol or phosphate-buffered saline (PBS)). BBWR mean \pm s.d. control $0.064 \pm 0.0063 \mathrm{~g}$, DEX $0.056 \pm 0.0049 \mathrm{~g}$. Pooled data from two independent litters, litter A: $n_{\text {control }}=6, n_{\mathrm{DEX}}=6$, litter B: $n_{\text {control }}=7 ; n_{\mathrm{DEX}}=7$. (b) DEX exposure on E14.5 leads to a decrease in the size of the cerebral cortex of the cortex by E17.5, $n_{\text {control }}=5$; control: $763 \pm 36 \mathrm{AU} n_{\text {control }}=6$; DEX: $667 \pm 18$ AU. Both the depth (c, white line) and surface area (d, black line, delimited by ${ }^{*}$ ) are reduced cortical in DEX-treated embryos compared to control: $120 \pm 3.8 \mathrm{AU}, \mathrm{DEX}: 105 \pm 8.3 \mathrm{AU}$. ${ }^{* * P}<0.01,{ }^{* * *} P<0.001$.

was a consequence of cell death, Terminal Deoxytidyl Transferase deoxy-uridine-triphosphate End Labeling (TUNEL) was examined at E17.5. No difference in TUNEL staining was observed between experimental and control animals in the cortical wall, which indicates that cell death does not contribute to the reduction in cortical depth at this age $\left(n_{\text {control }}=5, n_{\mathrm{DEX}}=5\right.$, mean \pm s.d., control $=0.75 \pm 0.03$, DEX $=0.58 \pm 0.4, P=0.55$ ).

The observation that cell death did not contribute to the reduction in the cortical size prompted us to examine whether organization of the cortex was altered and whether the deep-tosuperficial positioning of cortical layers was preserved. Markers of distinct laminae were identified by immunohistochemical staining with the following antibodies: layer VI (Tbr1+), layer V (Ctip2+), layer IV (Satb2+) and layer II/III (Cux1+). Visualization of stained sections revealed that the deep-to-superficial position of layers was not altered in DEX-treated animals; however, visual inspection of cortical sections from control versus DEX-exposed animals stained with the superficial laminar markers Satb2/Ctip2/Cux1 suggested that the number of neurons might differ between the two groups (Supplementary Figure 1A-D, $n_{\text {control }}=4, n_{\mathrm{DEX}}=4$ ).
To evaluate this possibility, the total number of cells (4,6-diamidino-2-phenylindole (DAPI)-positive) in the subplate and cortical plate at E17.5 was quantified. Interestingly, despite having a thinner cortex, DEX-exposed embryos had an increased number and density of DAPI+ cells in their cortical plate (Figures 2a-c, mean \pm s.d. cell number, control $825 \pm 29$, DEX $1021 \pm 44 P<0.01$; cell density (cells per $\mathrm{mm}^{2}$ ), control $7.6 \pm 0.2$, DEX $10 \pm 0.4, P<0.0002, n=5$ per treatment group).

To determine whether the increase in the number of cells within the cortical plate was due to a contribution from a specific cell type or cortical layer, or a general increase in the number of neurons across all cortical layers, we quantified the number of laminar-specific neurons in each layer by immunohistochemical staining for neuron and glial markers (Figures 2a-f). Cells were not positive for the glial cell marker glial fibrillar acidic protein, as expected for this embryonic age, indicating that DEX did not promote precocious gliogenesis (results not shown). However, for neuronal markers, DEX-exposed embryonic cortices exhibited a $64 \%$ increase in the number of layer $\mathrm{V}$ Ctip2+ cells (control $253 \pm 23$, DEX $415 \pm 33, P<0.001$ ), a $32 \%$ increase in the number 


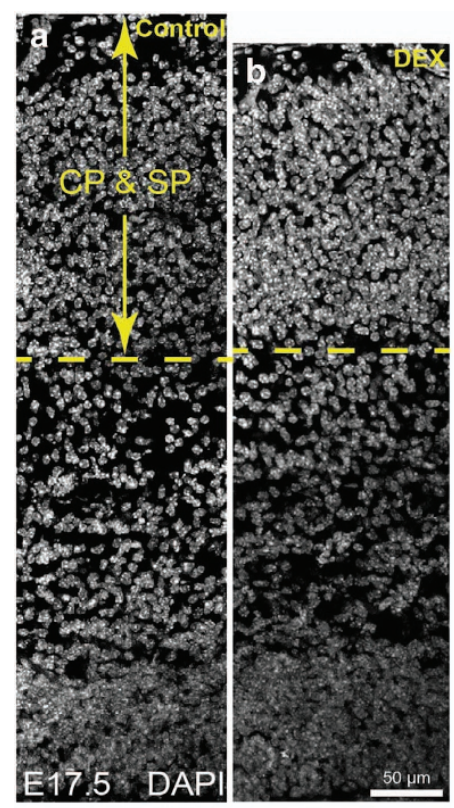

\section{C}

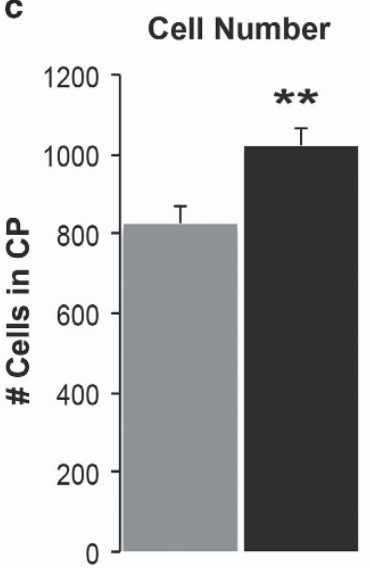

Cell Density

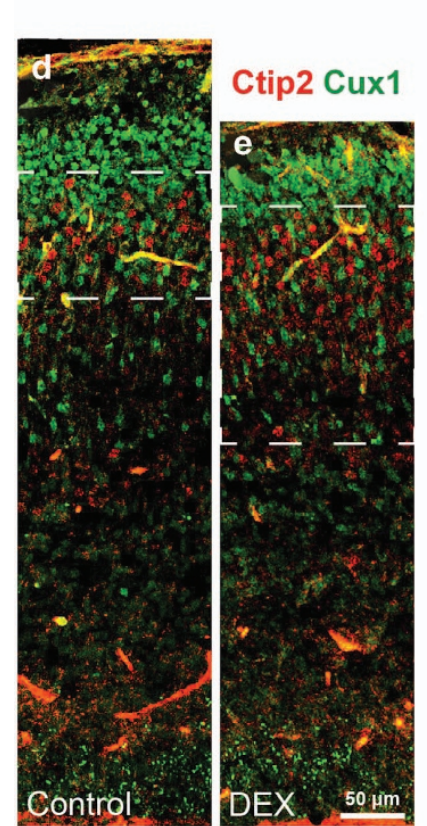

f
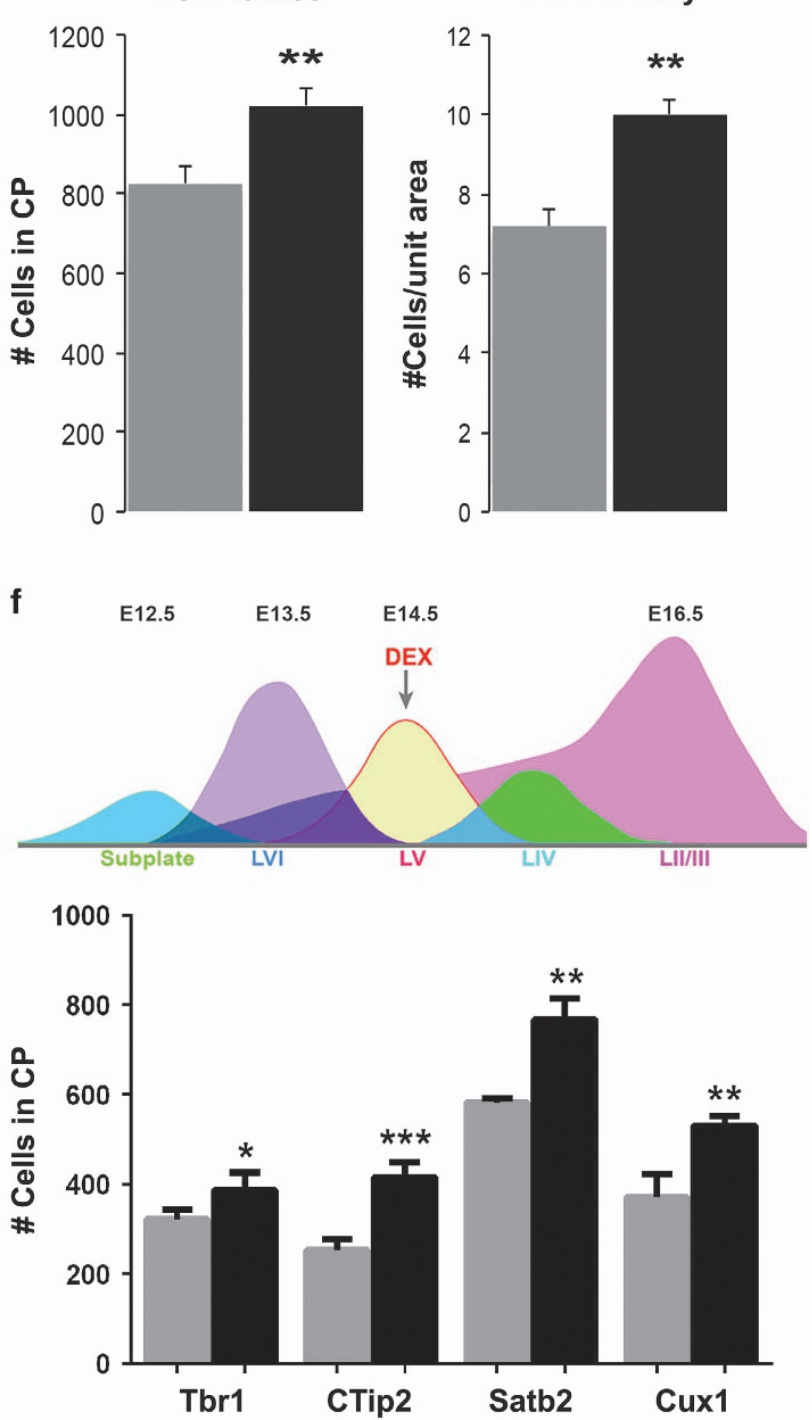

Figure 2. Dexamethasone (DEX) exposure on E14.5 results in an increased number of cells in the cortical plate and promotes supernumerary neuron production by E17.5. (a, b) Representative images of the cerebral wall in the somatosensory cortex at E17.4 in mice treated with DEX (b) or vehicle (a) at E14.5. (c) Prenatal DEX exposure leads to an increased number of cells (c) and density (d) in the cortical plate. Number of DAPI cells in the cortical plate \pm s.d., $n=4 ;{ }^{*} P<0.001$. Scale bar $50 \mu \mathrm{m}$. (d-f) Quantification of the number of distinct neuronal subtypes in each cortical layer. Top right, schematic representation of neuron production in the cerebral cortex at distinct gestational ages. Neuronal production of layer $\mathrm{V}(\mathrm{LV})$ reaches its maximum on E14.5 when DEX was given, while the production of upper layers LII-IV is steadily increasing. (d, e) Representative images of the cerebral wall in the somatosensory cortex at E17.4 stained with antibodies CTip2 to identify LV (red) and Cux1 to identify layers II/III (green) in mice treated with DEX (e) or vehicle (d) at E14.5. (f, histogram). DEX exposure causes an increase in the production of neurons in all layers in the cortical plate (delineated by dotted lines in $\mathbf{d}$, quantified in e with maximum effect on LV, where the cell number is increased by $64 \%$ compared to controls. Number of layer marker-positive cells \pm s.d., $n_{\text {control }}=3, n_{\text {DEX }}=4 ;$ Tbr 1 : control $322 \pm 21$; DEX $387 \pm 39, P<0.05$; Ctip2: control 253 \pm 23 , DEX $415 \pm 33$; Satb2: control $581 \pm 10$, DEX 767 \pm 47 ; Cux1: control $371 \pm 52$, DEX $530 \pm 21)$. Scale bar $50 \mu \mathrm{m} .{ }^{*} P<0.05,{ }^{* *} P<0.01,{ }^{* *} P<0.001$

of layer IV Satb2+ cells (control $581 \pm 10$, DEX $767 \pm 47, P<0.01$ ) and a $43 \%$ increase in the number of layer II/III Cux $1+$ cells (control $371 \pm 52$, DEX $530 \pm 21, \quad P<0.01$ ), compared to controls (Figures $2 d-f$ ). As neurons destined for upper layers IV-II are still migrating on E17.5 (as seen in Figures 2d and e), these percentages likely underestimate the total number of neurons generated in response to antenatal DEX exposure. Therefore, premature DEX-induced GR signaling at mid-gestation in the mouse leads to a global increase in neurogenesis without altering cell survival. 
A single exposure to DEX on E14.5 increases the number of NSPCs progressing through the $S$ phase

The increase in neuron number at E17.5 likely reflects an increased production of neurons from NSPC between E14.5, when DEX exposure occurred, and E17.5, when the brains were analyzed.
To determine whether neuronal output was increased on the day of DEX exposure, neurons born on E14.5 were identified by their incorporation of 5-bromodeoxyuridine (BrdU). Pregnant mice were simultaneously injected with BrdU and DEX or vehicle on E14.5. Embryos were allowed to develop for $72 \mathrm{~h}$ in utero, and the
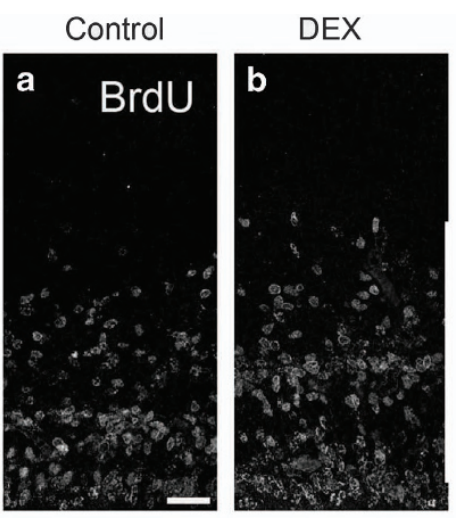

c

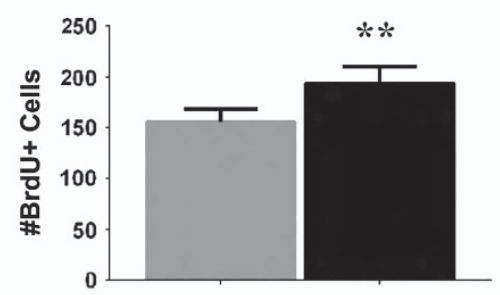

g
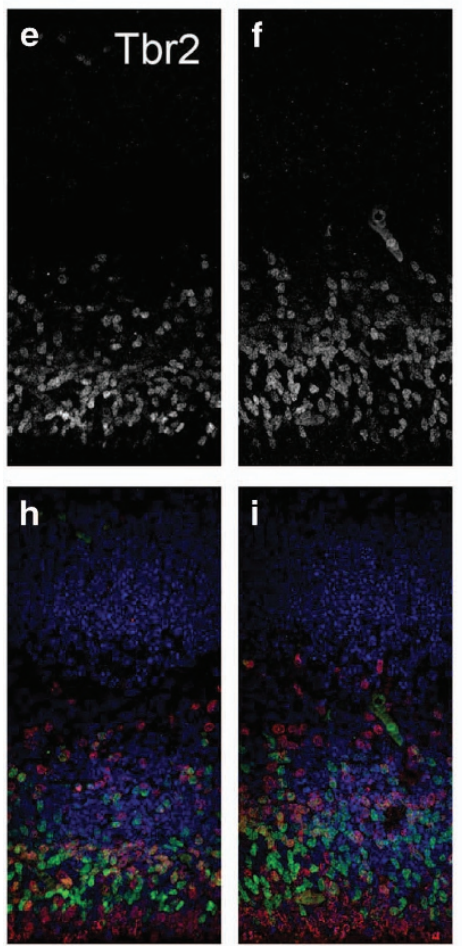

DAPI Tbr2 BrdU
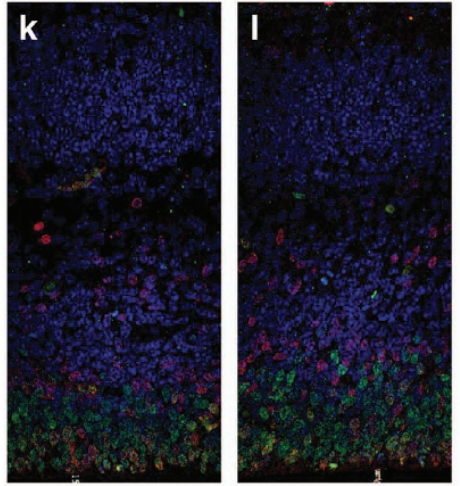

DAPI Pax6 BrdU

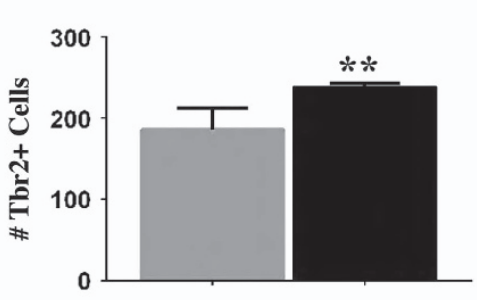

j

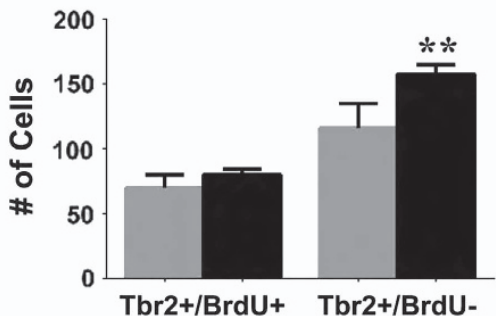

m

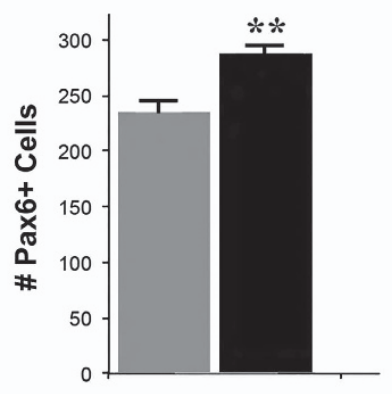

d

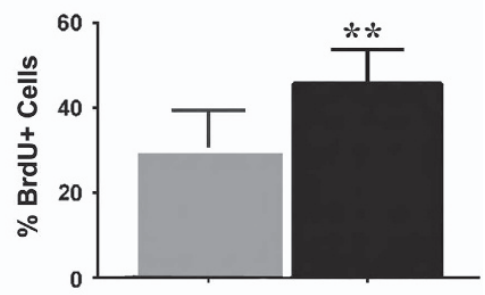

Control

DEX n

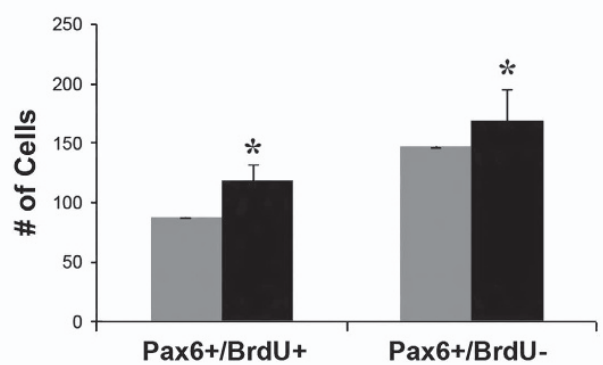


number of BrdU+ cells and their distribution across the cortical wall were quantified. Because the half-life of BrdU in vivo is estimated to be $\sim 5 \mathrm{~h}$ in the brain, ${ }^{29}$ this strategy allowed us to trace the number and position of a cohort of progeny born from E14.5 NSPCs that were in the S phase during the initial phases of DEX exposure. Interestingly, DEX exposure on E14.5 leads to a 39\% increase in the total number of BrdU-labeled cells in the cortical wall by E17.5 (control $208 \pm 23$ cells, DEX $290 \pm 28, P<0.001$, Supplementary Figure 2). Examining the distribution of BrdU+ cells throughout the cortical wall demonstrated that DEX-exposed embryonic cortices contained a greater proportion of BrdU+ cells in the cortical plate $(+19 \%$, Bins $6-10$, Supplementary Figure $2 d-f)$. This increase was accompanied by a decrease in the proportion of BrdU-labeled cells in the deeper cortical regions within the progenitor zone (Supplementary Figure 2d-f. Bins 1-3, $-15 \%$ ) and the intermediate zone (Supplementary Figure $2 d-f$ Bin 4,-16\%). Collectively, these results indicate that increased neuron production is a primary response to a single antenatal DEX exposure.

Previous studies have shown that DEX inhibits proliferation of embryonic NPCS in vitro, and adult progenitor cells in vivo, and stimulate differentiation and apoptosis in both human and animal studies. ${ }^{16,30}$ We hypothesized that the in vivo changes that were observed in in neurogenesis in our animal model reflected a direct effect of DEX on NSPCs to enhance cell cycle exit and thus stimulate neuron production at the expense of progenitor production. Therefore, we examined the immediate consequence of DEX exposure on NSPC proliferation at E14.5. Depending on the type of progenitor cell, the cell cycle is $\sim 19-26 \mathrm{~h}$ on E14.5, with the $S$ phase taking $\sim 3-8 \mathrm{~h}^{31}$ Therefore, to examine the effect of DEX within one cell cycle, E14.5 embryos were exposed to DEX or vehicle and BrdU (to label proliferating cells in the $S$ phase of the cell cycle) and collected $24 \mathrm{~h}$ later, and the number of BrdUpositive cells was quantified in the dorsal cerebral wall. A $24 \%$ increase in the number of BrdU-positive cells was observed in DEX-exposed embryos compared to vehicle after $24 \mathrm{~h}$ (Figures 3ac, number of BrdU+ cells \pm s.d., $n_{\text {control }}=4, n_{\mathrm{DEX}}=6$; control: $156 \pm 12$, DEX $194 \pm 16, P<0.01$ ). To verify these findings, the entire dorsal cerebral hemispheres were dissected from embryos exposed to DEX or vehicle plus BrdU for $24 \mathrm{~h}$ and processed for fluorescent-activated cell sorting (FACS). A $56 \%$ increase in the proportion of BrdU-labeled cells was observed (Figure 3d, \%BrdUpositive cells \pm s.d., $n_{\text {control }}=6,29 \pm 10, n_{\mathrm{DEX}}=7,49 \pm 6, P<0.01$ ). The larger increase in the proportion of labeled cells observed by FACS (56\%) compared to histological counts (24\%) is not surprising, given that the entire dorsal hemisphere, encompassing all cortical regions, was used for FACS analysis, compared to the $150-\mu \mathrm{m}$ window analyzed for the histological analysis. Therefore, the immediate effect of DEX exposure at E14.5 in vivo is to increase the number of cells progressing through $S$ phase of the cell cycle in vivo and not to promote cell cycle exit as observed in vitro and in adult hippocampal NSPCs.

DEX exposure at E14.5 results in an increase in the number of progenitor cells in a cell cycle-dependent manner

In all, $70 \%$ of the neurons in the adult cerebral cortex are produced from two distinct progenitor populations: RGCs and IPCs from E14.5. ${ }^{32}$ The two progenitor populations have distinct modes of proliferation that dictate their different neurogenesis potentials. Specifically, RGCs divide symmetrically to give rise to two RGCs (self-renewing divisions, $30 \%$ ) or asymmetrically to generate an RGC and either an IPC (30\%) or an outer RGC or a neuron (40\%). ${ }^{31}$ At E14.5, the IPC population significantly increases, with neurogenic divisions predominating (80\%). ${ }^{31}$ We have previously shown that GR is localized within different subcellular compartments within RGCs and IPCs from E11.5 to birth, potentially reflecting different functions of $\mathrm{GR}^{20}$ We therefore rationalized that the increase in neuron number could be due to increased proliferation in RGCs, IPCs or both, and therefore evaluated whether one population was selectively sensitive to DEX by staining brain sections from embryos exposed for $24 \mathrm{~h}$ to DEX or vehicle, for Pax6, a marker of RGCs, or Tbr2, a marker of IPCs. A $28 \%$ increase in the total number of IPCs (\#Tbr2+ cells \pm s.d., $n_{\text {control }}=4, n_{\text {DEX }}=6$; control: $186 \pm 27$, DEX $238 \pm 5.5, P<0.01)$ and a $30 \%$ increase in the number of RGCs (\#Pax6+ cells, $n_{\text {control }}=4, n_{\text {DEX }}=6$; control: $230 \pm 20$, DEX $280 \pm 5.5, P<0.01)$ was observed in DEX-exposed embryos compared to the controls (Figures $3 \mathrm{~g}$ and $\mathrm{m}$ ). As this increase in cell number was observed within one cell cycle, this indicates that a primary response to DEX is to stimulate the production of both RGCs and IPs.

Our studies, thus far, evaluated the consequences of DEX exposure on cells in the $S$ phase of the cell cycle; however, GR activity, phosphorylation and subcellular trafficking are differentially regulated in distinct phases of the cell cycle. ${ }^{33}$ To investigate the possibility that GC exposure preferentially influences cells in a distinct phase of the cell cycle, E14.5 embryos were exposed in utero to DEX or vehicle and BrdU for $24 \mathrm{~h}$. BrdU has a relatively short half-life in vivo and, thus, will label a cohort of cells progressing through the $S$ phase of the cell cycle during the first 5-6 h of exposure to DEX. ${ }^{34}$ BrdU-negative cells will be in $G 2$, M, G0 or G1 phases of the cell cycle during DEX exposure. Double-immunostaining was, therefore, performed with BrdU/ Tbr2 or BrdU/Pax6. BrdU+ and BrdU - cells were then assessed for dual labeling with each marker. Our results revealed that a 2-h DEX exposure leads to a $36 \%$ increase in the number of $\mathrm{Tbr} 2$ $+/$ BrdU - but no significant difference in the number Tbr2+/BrdU + cells (number of Tbr $2+/ \mathrm{BrdU}-$ cells \pm s.d., $n_{\text {control }}=4, n_{\mathrm{DEX}}=6$; control: $116 \pm 19$, DEX $158 \pm 7.3, P<0.01$, Figures $3 \mathrm{~h}-\mathrm{j}$ ). Interestingly, for RGCs, cells responded to DEX stimulation irrespective of the cell cycle phase, with an increase of $44 \%$ in the Pax6+/BrdU+ RGCs (number of $\mathrm{Pax}+/ \mathrm{BrdU}+$ cells \pm s.d., $n_{\text {control }}=4, n_{\mathrm{DEX}}=4$;

Figure 3. A 24-H dexamethasone (DEX) exposure at E14.5 results in an increase in the number of progenitor cells in a cell cycle-dependent manner (a-d). A single DEX exposure on E14.5 increases the number of NSPCs progressing through the S phase within $24 \mathrm{~h}$. A $24 \%$ increase in BrdU+ cells was quantified in DEX compared to control embryos, by BrdU immunofluorescence in a $150 \mu \mathrm{M}$ lateral to medial window in the dorsal cortex $(\mathbf{a}, \mathbf{b})$. (c) Histogram representing the number of BrdU+ cells per $150 \mathrm{mM}$ window \pm s.d., $n_{\text {control }}=4, n_{\mathrm{DEX}}=6$; control: $156 \pm 12$, DEX $194 \pm 16,{ }^{*} P<0.01$. (d) FACS analysis of the entire dorsal cortices' exposed to DEX or vehicle on E14.5 for $24 \mathrm{~h}$ validated the histological quantification and revealed a $56 \%$ increase in BrdU-labeled cells in response to DEX compared to control values. \%BrdU-positive cells \pm s.d., $n_{\text {control }}=6,29 \pm 10, n_{\text {DEX }}=7,49 \pm 6,{ }^{* *} P<0.01$. (e-n) DEX leads to an increase in the number of radial glial cells (RGCs) and intermediate progenitor cells (IPCs) in a cell cycle-specific manner within $24 \mathrm{~h}$. A 24-h exposure to DEX at E14.5 leads to (e-g) a $28 \%$ increase in the number of intermediate progenitor cells (Tbr2+) and a $20 \%$ increase in the number of RGCs (Pax6+, k-I). Number of Tbr2+ cells \pm s.d., $n_{\text {control }}=4$, $n_{\mathrm{DEX}}=6$; control: $186 \pm 27$, DEX 238 $\pm 5.5, P<0.01$. For Pax6, $n_{\text {control }}=4, n_{\mathrm{DEX}}=6$; control: $230 \pm 20, \mathrm{DEX} 2280 \pm 5.5, * * P<0.01$. (h-j) The increase in the IPC population was due to an increase of the IPCs that had not progressed through the $S$ phase during the initial stages of DEX exposure (Tbr2+/BrdU -). Number of Tbr2+/BrdU - cells \pm s.d., Student's $t$-test, $n_{\text {control }}=4, n_{\mathrm{DEX}}=6 ;$ control: $116 \pm 19, \mathrm{DEX} 158 \pm 7.3$, ${ }^{* *} P<0.01$. (k-n) DEX promotes increase of $44 \%$ in the $S$ phase Pax6+/BrdU+ RGC population and a $22 \%$ increase in the non-S-phase Pax6 $+/$ BrdU-RGC population compared to control embryos. ${ }^{*} P<0.05$. 


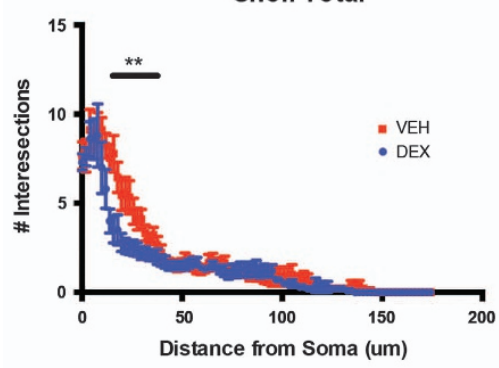

d

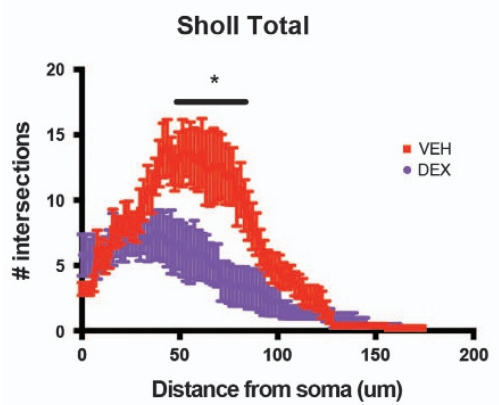

g

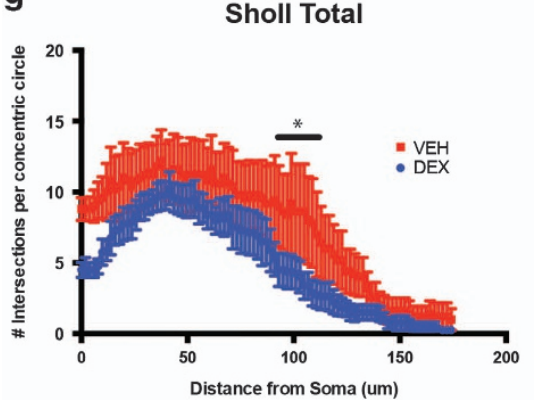

b

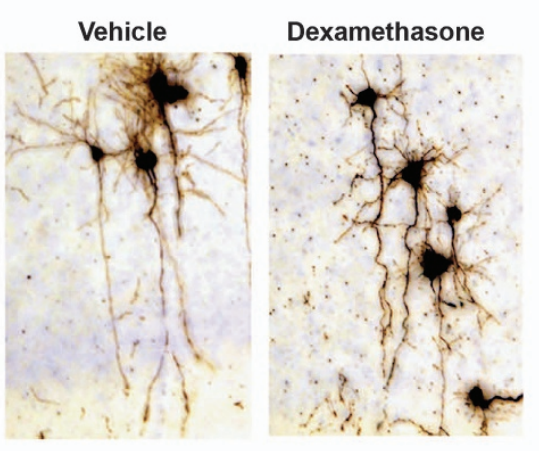

e

Dorsal Hippocampal Formation
CA1

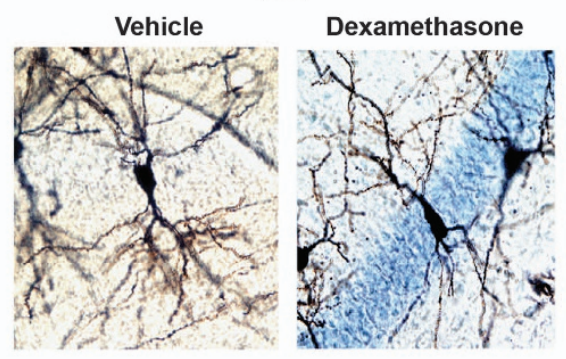

h

Dorsal Hippocampal Formation CA2/3

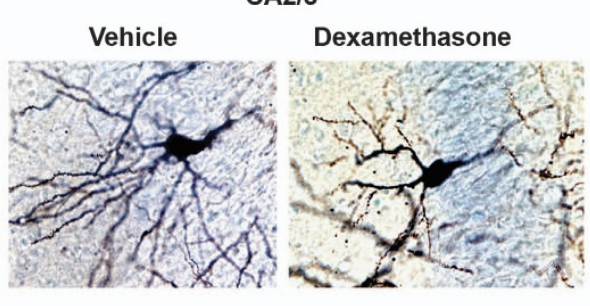

C

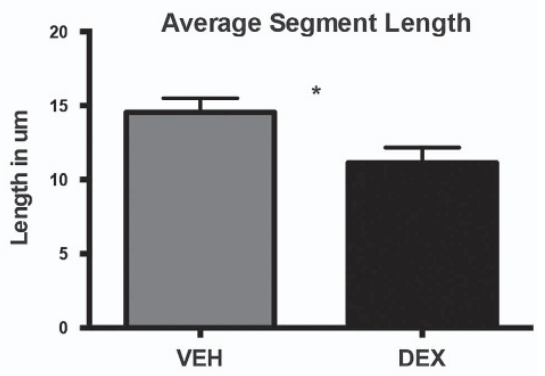

f

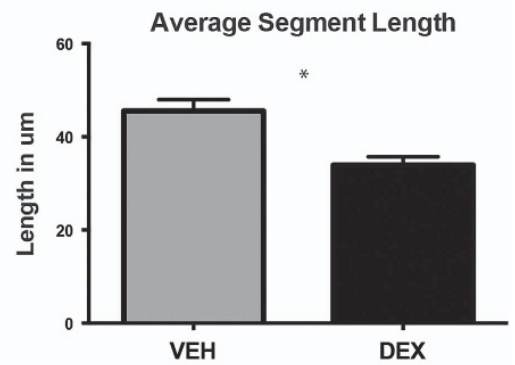

i

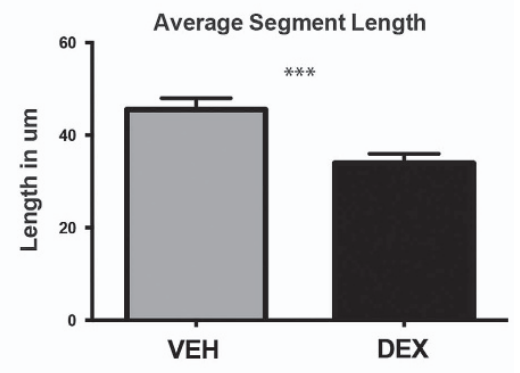

Figure 4. Prenatal exposure to dexamethasone (DEX) leads to long-term changes in neuronal architecture in the prefrontal cortex and hippocampus. Scholl analysis of postnatal day-10 brains from animals treated in utero on E14.5 with $0.4 \mathrm{mg} \mathrm{kg}^{-1} \mathrm{DEX}$ or vehicle. (a, d, g) The number of intersections (a measurement of neuronal complexity) at increasing distance from the soma is plotted for DEX (blue) versus control animals (red) in the anterior cingulate (a), the CA1 (d) and CA2 (g) regions of the hippocampus. (b, e, h) Representative Golgi-stained images of the areas and neurons used for analyses in the anterior cingulate (b), the CA1 (e) and CA2 (h) regions of the hippocampus. (c, $\mathbf{f}$, i) Histograms representing quantification of the distance between neurite branches (average segment length) are shown for the anterior cingulate $(\mathbf{c})$, the CA1 (f) and CA2 (i) regions of the hippocampus. ${ }^{*} P<0.05,{ }^{* *} P<0.0,{ }^{* *} P<0.001$.

control: $62 \pm 12.8$, DEX $89.5 \pm 11, P<0.05)$ and $22 \%$ in the Pax6+/BrdU - RGCs, compared to vehicle-exposed embryos (number of Pax+/BrdU - cells \pm s.d., control: $109.4 \pm 15.5$, DEX $133.4 \pm 3.9, \quad P<0.05$, Figures $3 \mathrm{k}-\mathrm{n})$. These results indicate that $\mathrm{sGCs}$ induce distinct biological responses in progenitor cells to produce RGCs versus IPCs depending on the phase of the cell cycle when the initial DEX exposure occurs. Irrespective of the cell cycle phase, RGCs respond to DEX by stimulating cell cycle re-entry and increasing the progenitor pool. Cells that were in the M or $\mathrm{G} 1$ phase at the time of initial exposure respond by re-entering the cell cycle to generate IPCs, while those cells in the $S$ phase of the cell cycle did not respond to DEX by expanding IPCs.

To evaluate whether this initial increase in the number of RGCs or IPCs persists in the E17.5 cortex ( $72 \mathrm{~h}$ after DEX exposure, 0.5 days before birth), the number of Pax6- and Tbr2-positive cells in the progenitor zone was assessed. The number of Pax6-positive cells was not different between controls and DEX-treated animals (number Pax6+ cells \pm s.d., $n_{\text {control }}=5 ; n_{\mathrm{DEX}}=5$., VZ: control 153.1 \pm 2.3 , DEX 155.2 $\pm 5.2 P=0.7$; SVZ: control 57.4 \pm 4.3 , DEX $56.6 \pm 1.1, P=0.7$, control total: $209.4 \pm 3.1$, DEX total: $212.2 \pm 4.9$, $P=0.6$, Supplementary Figure $3 A$ ). However, the number of Tbr2positive cells remained increased by $17 \%$ (number of Tbr2-positive cells in each zone \pm s.d., $n_{\text {control }}=4 ; n_{\mathrm{DEX}}=4$. progenitor zone: control 122 \pm 4.2 , DEX $144 \pm 3.3$. intermediate zone: control $34 \pm 2.7$, DEX 38 \pm 2.6 , control total: $209.4 \pm 3.1$, DEX total: $212 \pm 4.1, P<0.01$, Supplementary Figure 3B). These findings indicate that a single exposure of DEX in utero leads to long-term changes in the proliferative capacity of embryonic NSPC and elicits distinct biological responses in different progenitor cell types that ultimately has an impact on the size and cytoarchitecture of the cerebral cortex perinatal. 
NSPC exhibits a dose-dependent proliferative and transcriptional response to DEX

Our observation that a single exposure to GCs at E14.5 leads to enhanced proliferation and neuronal differentiation in the cerebral cortex is in contrast to previous in vitro studies, demonstrating that $10^{-7} \mathrm{M}$ DEX impaired the proliferation of NSPCs. ${ }^{16,20,30,35} \mathrm{We}$ postulated that the dose of DEX that cortical NSPCs are exposed in vivo could be lower than that reported in blood because of differences in blood-brain barrier penetration, and diffusion into or transport out of the cell. ${ }^{36}$ Therefore, to determine whether the proliferative response of NSPCs to DEX was dose-dependent, primary neural stem cell cultures were established from the E14.5 cerebral cortex and exposed to decreasing doses of DEX $\left(10^{-7}\right.$, $10^{-8}$ and $10^{-9} \mathrm{M}$ ) for $18 \mathrm{~h}$ and then assayed for the cellular proliferation rate. A dose-dependent decrease in cellular proliferation was observed. At lower concentrations of DEX $\left(10^{-9} \mathrm{M}\right)$, proliferation was significantly enhanced $(10 \% P<0.001)$, whereas at higher concentrations DEX inhibited proliferation $\left(10^{-8} \mathrm{M}, 5 \%\right.$ decrease; $10^{-7} \mathrm{M} 10 \%$ decrease ${ }^{*} P<0.01,{ }^{*} P<0.001, n=5$, Supplementary Figure 4A).

We have previously identified over 200 genes in cortical NSPC cultures that are induced or repressed in response to $4 \mathrm{~h}$ of DEX exposure using gene array and RNAseq ${ }^{30}$ analyses. Ingenuity pathway analysis of RNAseq results indicated that cell cycle networks were one of the top DEX-regulated pathways. We reasoned that the dose-dependent changes in the proliferative responses to DEX might be mediated by changes in gene expression of some of these cell cycle regulators. Therefore, we used a cell cycle RT-PCR array from 'Superarray' to directly compare the changes in gene expression in isolated cerebral cortices' exposed to $10^{-7} \mathrm{M}$ DEX or vehicle for $6 \mathrm{~h}$ in vivo and compared the results to data obtained from our in vitro RNAseq studies. $^{37}$ We identified four genes that exhibited differential regulation in vivo versus in vitro. Of relevance are two GC target genes, Promyelocytic Leukemia Zinc Finger $\left(P L Z F / Z B T B 16^{38}\right)$ a glucocorticoid-regulated target implicated in cell cycle arrest and Peripheral Myelin Protein 22 (PMP22). ${ }^{39}$ Increased expression of PLZF/ZBTB16 and PMP22 $(P<0.01, N=3)$ is associated with growth arrest. As shown in Supplementary Figure 4b, PLZF/ ZBTZ16 and PMP22 mRNA expression in E14.5 cerebral cortical tissue in vivo was decreased upon $6 \mathrm{~h}$ of antenatal DEX exposure (PLZF $P<0.001, N=3$, PMP22, $P<0.01, N=3$ ) but was increased in primary embryonic NSPC cultures in vitro in response to a concentration of DEX that is antiproliferative. ${ }^{37}$ In contrast, the expression of the cyclin-dependent kinase, CDK2, which promotes cell cycle re-entry, was elevated in vivo $(P<0.0001, N=3)$ but not in vitro (Supplementary Figure $4 \mathrm{~B}$ ). These findings support the hypothesis that distinct transcriptional responses observed in vivo versus in vitro were a consequence of exposure to different intracellular concentrations of GC.

To validate the dose-dependent response of select GR targets, we further exposed NSPCs to decreasing concentrations of DEX or ethanol for $4 \mathrm{~h}\left(10^{-7}, 10^{-8}\right.$ or $10^{-9} \mathrm{M}$ DEX; $\left.n=8\right)$ and examined the response of four known GR target genes implicated in proliferation (PLZF, GILZ, FKBP and SGK1) and four additional novel GR target genes identified in our RNAseq studies (PTK2B, KLF4, KLF9 and FAM107a; Supplementary Figure 4c) by quantitative RTPCR. A dose-dependent response was observed with all of the genes examined, with some genes showing minimal activation at $10^{-9} \mathrm{M}$ DEX but 50 - to 100 -fold activation at $10^{-7} \mathrm{M}$ DEX (PTK2B, FAM107a and SGK), others showing significant activation at $10^{-9} \mathrm{M}$ DEX and enhanced activation at $10^{-7} \mathrm{M}$ DEX (GILZ and KLF9), with KLF4 exhibit repression at $10^{-7} \mathrm{M}$ DEX compared to $10^{-9} \mathrm{M}$ DEX (Supplementary Figure S4C-E). Together, these findings indicate that neural stem and progenitor cells activate unique transcriptomes in respond to GCs in a dose-dependent manner to regulate the proliferative versus antiproliferative properties of NSPC.

Antenatal DEX exposure leads to decreased neuronal complexity in the prefrontal, somatosensory cortex and granule cell layer of the dentate gyrus

In our antenatal sGC paradigm, a single dose of DEX at E14.5 decreased the depth of the cerebral cortex and brain size despite enhancing proliferation of distinct progenitor cell populations. Neuronal processes contribute significantly to overall mass, and, if reduced in length, complexity or number by antenatal DEX, could result in a reduced cortical size. We therefore examined neuronal complexity in DEX-exposed mice at postnatal day 10, an age at which dendritic arborization would be much more elaborate than at E17.5 and therefore reveal long-term changes in neuronal maturation. Term-born children exposed to GCs in utero exhibit a thinner anterior cingulate; ${ }^{13}$ therefore, we focused on this area for our initial analyses in mice. Individual pyramidal neurons in the anterior cingulate were visualized by Golgi impregnation and quantified by Sholl analyses in P10 mice exposed to DEX or vehicle on E14.5. DEX altered the morphology of pyramidal cells with a significant decrease in complexity. DEX-treated animals exhibited fewer neurite branches close to the soma (Figure $4 a$, significant difference identified $10-29 \mu \mathrm{m}$ from soma; $P<0.005, n_{\text {control }}=9$; $n_{\mathrm{DEX}}=10$ ), and the distance between branches (average segment length) was reduced compared to controls (Figures $4 \mathrm{~b}$ and $\mathrm{C}$, $n_{\text {DEX }}=10,14.55 \pm 0.96$ um, $n_{\text {control }}=9,11.13 \pm 1.04$ um, $P<0.05$ ). To determine if these abnormalities were unique to pyramidal neurons in the anterior cingulate, or if the deficits were more widespread, we examined the morphology of pyramidal neurons in the CA 1 and CA2/3 region of the hippocampus, an area known to be highly sensitive to GCs due to the high density of GRs in the embryonic stage. As shown in Figures $4 \mathrm{e}-\mathrm{h}$, hippocampal pyramidal neurons exposed to DEX antenatally were also less complex than cells from animals exposed to vehicle. However, CA1 and CA2 neurons exhibit a different sensitivity to prenatal DEX exposure. Pyramidal cells in CA1 had a decreased number of neurite branches (Figures $4 \mathrm{~d}$ and $\mathrm{e}, n_{\text {control }}=5 ; n_{\mathrm{DEX}}=5, P<0.002$, 41-81 um from soma) with an increased distance between branch points (Figure 4f, Comtrol mean 28.5 \pm 1.7 , DEX 37.99 \pm 4.4 um; $P<0.05$, mean segment length $\left.n_{\text {control }}=5 ; n_{\mathrm{DEX}}=5\right)$, whereas in CA2 neurons, the number of neurite branches was altered further from soma (Figures $4 \mathrm{~g}$ and $\mathrm{h} ; n_{\mathrm{DEX}}=8, n_{\text {control }}=5,91-110 \mathrm{um}$ from soma), and the average segment length was decreased among DEX-exposed animals (Figure 4i, VEH mean $45.55 \pm 2.4 \mu \mathrm{m}$; DEX mean $\left.33.9, \pm 1.8 \mu \mathrm{m} ; P<0.0005, n_{\text {control }}=5 ; n_{\mathrm{DEX}}=8\right)$.

Antenatal administration of DEX leads to alterations in behavior in the adult mouse

In light of the cognitive and behavioral abnormalities reported in children exposed to sGCs in utero, we asked whether a single exposure to DEX at E14.5 could alter adult behavior. Adult male mice (P60) exposed to DEX or vehicle on E14.5 were examined in the open field, elevated plus and forced swim $(N=8-12)$. No obvious difference in the general physical appearance or behavior (grooming, feeding, maternal behavior, response to sound or vision) was observed between experimental and control animals. In the open field test, no difference in the distance traveled $(P<0.5)$, ambulatory time $(P<0.2)$, resting time $(P<0.6)$ or travel speed (Figure $5 a$ ), $P=0.6$, was observed between DEX- or vehicleexposed mice, which indicates that motor circuits are not disrupted. However, antenatal DEX-exposed mice spent significantly more time in the center of the open field compared to controls, a behavioral outcome suggestive of a change in basal anxiety levels (Figures 5a-d; 231.2 versus $434 \mathrm{~s}, P<0.006$ ). Animals were then tested in a second test, the elevated plus maze, a widely used anxiogenic test in mice. Antenatal DEX- 
10
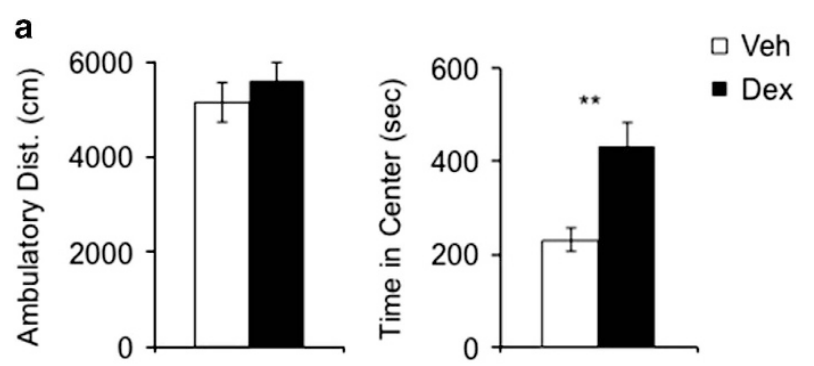

b
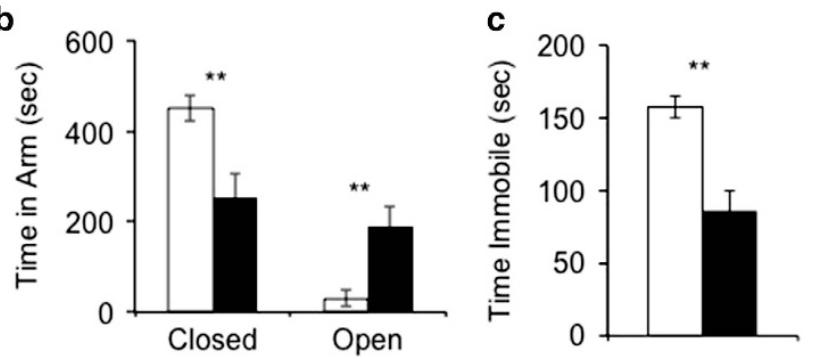

Figure 5. In utero glucocorticoid (GC) administration leads to longterm changes in behavior. Adult male animals (P60) treated with dexamethasone (DEX) at E14.5 are shown in black compared to vehicle (ethanol)-treated animals shown in gray in the open field test (a), the elevated plus maze test (b) and the forced swim test (c). DEX-treated animals spent more time in the center of the open field (a, right), increased time in the open arms and decreased time in the closed arms of the elevated plus maze (b), and less time floating in the forced swim test compared to Controls ( $N=6-10$ per treatment). ${ }^{*} P<0.001$.

exposed mice spent significantly less time in the closed arms (450.9 versus $254.9 \mathrm{~s}, P<0.009)$ and more time in the open arms (Figure 5b, 30.4 versus $190.1 \mathrm{~s}, P<0.01$ ). Given that anxiety and depression are often associated, we then measured the animals' behavior in the forced swim test, an assay for depressive-like behavior in mice. ${ }^{40}$ DEX-exposed animals spent less time immobile compared to controls, which suggests that they were more resilient to the acute stress induced in this test (Figure $5 c$, 58.1 versus $86.2 \mathrm{~s}, P<0.001)$. Together, these findings indicate that a single DEX administration in utero can lead to long-term changes in anxiolytic and antidepressive-like behavior in adult mice.

\section{DISCUSSION}

Antenatal administration of sGCs to mothers at risk of preterm delivery causes a significant reduction of infant morbidity and mortality. ${ }^{41-44}$ However, both animal and human studies have revealed adverse effects of antenatal sGCs on neurodevelopment in the fetus, with consequences later in life on cerebral cortical and hippocampal architecture and behavior. ${ }^{13,43,44}$ In this report, we utilized a single dose of antenatal DEX during mouse development that approximates the neurodevelopmental events and steroid-naive environment present in human fetuses at the time of exposure to sGC treatment. Importantly, similar to studies in humans, the antenatal sGC treatment in our studies occurred at a time when exposure of the brain to endogenous GCs is minimal (reviewed in Peffer et al. ${ }^{16}$ and Frahm et $a .^{37}$ ). Our studies demonstrate that a single clinically relevant dose of sGCs elicits distinct responses in different neural progenitor cell types within $24 \mathrm{~h}$. These changes lead to long-term changes in neuronal composition, cerebral architecture and changes in emotional behavioral responses such as anxiety and depression. The relevance of our animal model to neurodevelopmental effects of antenatal sGC in humans is evidenced by our observed reduction in cortical size and alterations in neuronal maturation and architecture in the anterior cingulate, both features that have been observed in newborn infants exposed in utero to sGCs. ${ }^{13}$

Several studies in human and animal models have examined the consequences of in utero DEX exposure on brain development and behavior. ${ }^{10,42}$ These studies revealed effects on cortical, cerebellar and hippocampal development, cerebral myelination and altered development of different neurotransmitter systems such as serotonin and dopamine. ${ }^{10,12,44,45}$ Moreover, through premature initiation of GC-GR signaling, the function of the hypothalamus pituitary adrenal axes HPA axis is altered, leading to a predisposition for a multitude of medical conditions ranging from metabolic to cardiovascular and neuropsychiatric conditions (reviewed in Huang ${ }^{46}$ ). While studies in both mice and human indicate that prenatal GC administration has significant consequences for neurodevelopment, few targets have been identified. By examining specific progenitor cell populations in vivo, we were able to isolate the actions of a single, clinically relevant dose of DEX on two distinct progenitor types, RGCs versus IPCs. Our results show that DEX promotes cell cycle re-entry and proliferation in all RGCs within one cell cycle. However, in IPCs, DEX only promotes expansion in cells that are in G2, M and G1 phases, while cells exposed to DEX in the $S$ phase of the cell cycle remain unchanged. What mechanisms might mediate to these diverse progenitor responses? The intracellular localization of the GR has been shown to dictate distinct intracellular responses. Previous studies have shown that the subcellular localization of the GR markedly changes with cell cycle phase. Cells in the interphase predominantly exhibit nuclear GR localization, whereas cells in late G2, M or early G1 exhibit cytoplasmic localization. ${ }^{38-40}$ We have previously shown that in the steroid-naive brain (E9.5 to E16.5) RGCs and IPCs exhibit distinct subcellular localization of GR. Ligand-independent nuclear localization of GR was observed in all IPCs but only in RGCs in the S phase of the cell cycle before E13.5, while RGCs entering (late G2) or exiting (early G1) or in M phase of the cell cycle, exhibit cytoplasmic GR localization. However, by E14.5, when DEX is administered, RGCs predominantly exhibit cytoplasmic GR localization and IPs retain strong nuclear and weak cytoplasmic localization. ${ }^{19}$ IPs primarily give rise to neurons destined for upper cortical layers at E14.5, and these neurons retain nuclear GR expression. ${ }^{19}$ While GR has primarily been studied for its effects on transcription in the nucleus, we have previously shown that activation of plasma membrane-associated GR activates a variety of intracellular signaling pathways, reduces gap junction intracellular communication and synchronizes $\mathrm{Ca}^{2+}$ oscillations in NSPCs. ${ }^{32,33}$ Cell cycle-specific mobilization of these intracellular pathways also leads to site-specific phosphorylation of the GR that ultimately influences GR activity and the cells' response to glucocorticoids. ${ }^{38-40}$

DEX, therefore, initially leads to expansion of the progenitor population and ultimately to increased production of neurons. Consistent with these findings, we observed an increase in neuron number not only in layers V IV, layers that are being specified at the time of sGC exposure (at E14.5), but also in neurons in layers II/ II, layers that are produced from E15.5 to E16.5 progenitors long after SGC exposure. Changes in the pattern of stem and progenitor cell proliferation have been proposed to the underlie expansion and elaboration of the cerebral cortex in humans. ${ }^{47}$ In addition to RGCs, in humans the SVZ is greatly expanded and consists not only of iPCs but also of a second population of distinct progenitor cells, the outer RGCs that have a significant contribution to cortical neuron production. ${ }^{48}$ In light of the dynamic changes that occur in these populations during development in humans, it will be critical to determine whether human ventricular RGCs, outer RGCs and IPCs exhibit similar sensitivities to sGCs.

The antiproliferative effects of sGCs observed in vivo and in vitro by many groups, ${ }^{30,35}$ including our own with primary NSPC 
cultures in vitro, are likely the consequence of stem and progenitor cell exposure to relatively high doses of GCs, as we observed enhanced proliferation of primary NSPC cultures at relatively low concentrations of DEX $\left(10^{-9} \mathrm{M}\right)$ and inhibitory responses on cell growth at relatively high DEX concentrations $\left(10^{-7} \mathrm{M}\right)$. These observations are consistent with human and animal studies that demonstrate increased neurodevelopmental abnormalities in children or animals exposed to high or multiple doses of sGC prenatally, ${ }^{5}$ effects that increase in severity with the gestational age. ${ }^{49}$ For example, comparing the consequences of low and high doses ( 1 or $3 \mathrm{mg} \mathrm{kg}^{-1}$ ) of DEX on rat brain development at three different developmental stages (E13, E16 and E19) demonstrated that $3 \mathrm{mg} \mathrm{kg}^{-1}$ produced more pronounced reductions in the number of neurons in all cortical layers in the cortex and hippocampus. At higher doses, neuron size was also reduced. ${ }^{50}$ In humans, repeated prenatal administration of sGCs leads to increasing deficits in brain size, body mass index and cortisol levels in elementary children. ${ }^{11,51}$ Furthermore, endogenous elevation of GCs, such as in situations of high maternal stress, leads to decreased proliferation in the dentate gyrus in offspring, impaired hippocampal-dependent learning and memory and impaired attention and behavioral problems. 2,3,50,52-59

Genome-wide analysis from our group ${ }^{37}$ and others ${ }^{39}$ has identified cell cycle networks containing multiple genes that have an impact on proliferation and/or survival of NSPCs to sGCs. As shown by our examination of specific target genes including CDK2, PMP22, FKBP, KLF9, SGK1, PTK2B, KLF4, KLF9, FAM107a and $P L Z F$ in vivo and in vitro, DEX can generate alterative molecular responses that could ultimately contribute to pro- or antiproliferative response of distinct stem or progenitor pools. These findings are consistent with studies that demonstrate dosedependent responses to GCs. For example, in neurons exposed to excitotoxic injury, a dose-dependent $U$-shaped curve has also been described for the neuroprotective versus neurodegenerative response to $\mathrm{sGC}^{60}$ Our results, therefore, suggest that the consequences of antenatal SGC treatment on proliferation in distinct stem and progenitor cell populations in human fetuses could be influenced by the precise dosing regimen of sGCs and genetic and/or environmental factors that have an impact on the delivery and accumulation of these compounds to the fetal brain.

Counter to expectations, our studies demonstrate that a single dose of DEX leads to decreased cortical surface area and depth that is associated with increased neuronal number. As neuronal migration was not examined in this study, we cannot rule out a role for GC in regulating migration; however, considering the observation that lamination is normal at birth (Supplementary Figure S1) and that neuronal ectopia is not observed in adults (not shown), migration deficits are likely to lead to more subtle deficits if present. Interestingly, we show that antenatal DEX exposure differentially reduces dendritic complexity in the prefrontal cortex and in the hippocampus. An emerging literature has demonstrated that repeated perinatal administration of sGCs and chronic antenatal or postnatal stress trigger dendritic atrophy. ${ }^{61}$ While multiple GR target genes are likely contributing to altered dendritic maturation or atrophy, our prior RNA-seq analysis identified brain-derived growth factor as a transcriptionally repressed gene in DEX-treated NSPC cultures. ${ }^{16,30}$ The GR and brain-derived growth factor pathways are interconnected at multiple levels, and both can influence dendritic spine maturation upon acute in vitro treatment of mature primary cortical neuron cultures. ${ }^{62}$ The possibility that of brain-derived growth factor/GR crosstalk in neural stem and progenitor cells could trigger longterm changes in dendritic maturation of differentiated neurons will be of interest to examine particularly in light of the role of sitespecific GR phosphorylation in brain-derived growth factor action in mature neurons ${ }^{62}$ and non-genomic/genomic GR action in NSPCs. ${ }^{16,30}$
The neuroanatomical changes in the adult cortex that result from alterations in the timing of the generation of distinct neuronal subtypes and progenitor cell expansion are subtle, but nonetheless have functional consequences, as revealed by our demonstration of significant alterations in anxiety and resilience behavior. While these studies have focused on changes in the cerebral cortex and hippocampus, we have previously reported changes in the hypothalamus in response to prenatal DEX administration. ${ }^{37}$ Even though it is difficult to equate specific anatomical abnormalities with distinct behavioral changes, it is interesting that similar changes in stress response and anxiety behavior have been observed in the Corticotropin-releasing hormone receptor (Crhr1)-deficient mice, ${ }^{63}$ a key mediator of the effects of GCs on the HPA axis.

In conclusion, we demonstrate that antenatal DEX administered during mid-gestation significantly alters the developing brain, leading to long-term alterations in the brain architecture and behavior. SGCs, when administered at a critical developmental window, disrupt cellular fate decisions leading to altered cortical anatomy and complexity. Our results recapitulate outcomes observed in steroid-exposed children, such as thinning of the cerebral cortex and the propensity to develop behavioral abnormalities. In addition, we provide insights into how sGCs may act at the cellular level in the embryo, adolescent and adult. More research is urgently needed to develop modifications to the antenatal dosing strategies in humans, so that the minimal beneficial dose for respiratory distress syndrome, NED and intraventricular hemorrhage is administered to protect the fetal brain during critical developmental periods when exposed to a drug that has proven to have life-saving benefits for preterm infants.

\section{CONFLICT OF INTEREST}

The authors declare no conflict of interest.

\section{ACKNOWLEDGMENTS}

We thank Marcia Lewis, Liping Wang and Alexis Franks for technical assistance. Parameter adjustment and analysis of the raw FACS data were performed by Dr Albert D Donnenberg and Mr Michael Meyer at the Cell Cytometry Facility of the University of Pittsburgh Cancer Institute (UPCI), supported in part by award P30 CA047904. These studies were supported by funding from the University of Pittsburgh Intramural Research Training Award Program (PADOHSAP\#4100047862, NK), an ACS grant (RSG-09-054-0 1-GMC, APM), G Harold and Leila Y Mathers Charitable Foundation Award (APM), a Nuclear Receptor Signaling Atlas (NURSA) Data Resource Project from an NIH U24 Grant DK097748 (APM, DD), NIH T32-HD07183401A1 (AR), NIH K12 HD052892-09 (AR), Magee-Women's Clinical Trainee Research Award (AR) and the University of Pittsburgh Medical Center Department of Pediatrics Endowed Instructorship (AR).

\section{REFERENCES}

1 Oakley $\mathrm{RH}$, Cidlowski JA. The biology of the glucocorticoid receptor: new signaling mechanisms in health and disease. J Allergy Clin Immunol 2013; 132: 1033-1044.

2 Moisiadis VG, Matthews SG. Glucocorticoids and fetal programming part 1: outcomes. Nat Rev Endocrinol 2014; 10: 391-402.

3 Moisiadis VG, Matthews SG. Glucocorticoids and fetal programming part 2: mechanisms. Nat Rev Endocrinol 2014; 10: 403-411.

4 Braun T, Challis JR, Newnham JP, Sloboda DM. Early-life glucocorticoid exposure: the hypothalamic-pituitary-adrenal axis, placental function, and long-term disease risk. Endocr Rev 2013; 34: 885-916.

5 Damsted SK, Born AP, Paulson OB, Uldall P. Exogenous glucocorticoids and adverse cerebral effects in children. Eur J Paediatr Neurol 2011; 15: 465-477.

6 Uno H, Lohmiller L, Thieme C, Kemnitz JW, Engle MJ, Roecker EB et al. Brain damage induced by prenatal exposure to dexamethasone in fetal rhesus macaques. I. Hippocampus. Brain Res Dev Brain Res 1990; 53: 157-167.

7 Modi N, Lewis H, Al-Naqeeb N, Ajayi-Obe M, Dore CJ, Rutherford M. The effects of repeated antenatal glucocorticoid therapy on the developing brain. Pediatr Res 2001; 50: 581-585. 
8 Noorlander CW, De Graan PN, Middeldorp J, Van Beers JJ, Visser GH. Ontogeny of hippocampal corticosteroid receptors: effects of antenatal glucocorticoids in human and mouse. J Comp Neurol 2006; 499: 924-932.

9 Noorlander CW, Tijsseling D, Hessel EV, de Vries WB, Derks JB, Visser GH et al. Antenatal glucocorticoid treatment affects hippocampal development in mice. PLOS ONE 2014; 9: e85671.

10 Spinillo A, Viazzo F, Colleoni R, Chiara A, Maria Cerbo R, Fazzi E. Two-year infant neurodevelopmental outcome after single or multiple antenatal courses of corticosteroids to prevent complications of prematurity. Am J Obstet Gynecol 2004; 191: $217-224$.

11 French NP, Hagan R, Evans SF, Mullan A, Newnham JP. Repeated antenatal corticosteroids: effects on cerebral palsy and childhood behavior. Am J Obstet Gynecol 2004; 190: 588-595.

12 Crowther CA, Doyle LW, Haslam RR, Hiller JE, Harding JE, Robinson JS et al. Outcomes at 2 years of age after repeat doses of antenatal corticosteroids. $N$ Engl J Med 2007; 357: 1179-1189.

13 Davis EP, Sandman CA, Buss C, Wing DA, Head K. Fetal glucocorticoid exposure is associated with preadolescent brain development. Biol Psychiatry 2013; 74: 647-655.

14 Davis EP, Waffarn F, Uy C, Hobel CJ, Glynn LM, Sandman CA. Effect of prenatal glucocorticoid treatment on size at birth among infants born at term gestation. J Perinatol 2009; 29: 731-737.

15 Murphy KE, Hannah ME, Willan AR, Hewson SA, Ohlsson A, Kelly EN et al. Multiple courses of antenatal corticosteroids for preterm birth (MACS): a randomised controlled trial. Lancet 2008; 372: 2143-2151.

16 Peffer ME, Zhang JY, Umfrey L, Rudine AC, Monaghan AP, DeFranco DB. Minireview: the impact of antenatal therapeutic synthetic glucocorticoids on the developing fetal brain. Mol Endocrinol 2015; 29: 658-666.

17 Ishimoto H, Jaffe RB. Development and function of the human fetal adrenal cortex: a key component in the feto-placental unit. Endocrine Reviews 2011; 32: 317-355.

18 Kapellou O, Counsell SJ, Kennea N, Dyet L, Saeed N, Stark J et al. Abnormal cortical development after premature birth shown by altered allometric scaling of brain growth. PLoS Med 2006; 3: e265.

19 Sinclair D, Webster MJ, Wong J, Weickert CS. Dynamic molecular and anatomical changes in the glucocorticoid receptor in human cortical development. Mol Psychiatry 2011; 16: 504-515.

20 Tsiarli MA, Paula Monaghan A, DeFranco DB. Differential subcellular localization of the glucocorticoid receptor in distinct neural stem and progenitor populations of the mouse telencephalon in vivo. Brain Res 2013; 1523: 10-27.

21 Khozhai L, Otellin V. Formation of neocortex and hippocampal structures after single action of dexamethasone during prenatal period of rat development. J Evol Biochem Physiol 2008; 44: 528-531.

22 Uno H, Eisele S, Sakai A, Shelton S, Baker E, DeJesus O et al. Neurotoxicity of glucocorticoids in the primate brain. Horm Behav 1994; 28: 336-348.

23 Sundberg M, Savola S, Hienola A, Korhonen L, Lindholm D. Glucocorticoid hormones decrease proliferation of embryonic neural stem cells through ubiquitinmediated degradation of cyclin D1. J Neurosci 2006; 26: 5402-5410.

24 Murphy BE, Sebenick M, Patchell ME. Cortisol production and metabolism in the human fetus and its reflection in the maternal urine. J Steroid Biochem 1980; 12: 37-45.

25 Venihaki M, Carrigan A, Dikkes P, Majzoub JA. Circadian rise in maternal glucocorticoid prevents pulmonary dysplasia in fetal mice with adrenal insufficiency. Proc Natl Acad Sci USA 2000; 97: 7336-7341.

26 Pulvers JN, Huttner WB. Brca1 is required for embryonic development of the mouse cerebral cortex to normal size by preventing apoptosis of early neural progenitors. Development 2009; 136: 1859-1868.

27 Roy K, Kuznicki K, Wu Q, Sun Z, Bock D, Schutz G et al. The Tlx gene regulates the timing of neurogenesis in the cortex. J Neurosci 2004; 24: 8333-8345.

28 Takahashi T, Goto T, Miyama S, Nowakowski RS, Caviness VS Jr. Sequence of neuron origin and neocortical laminar fate: relation to cell cycle of origin in the developing murine cerebral wall. J Neurosci 1999; 19: 10357-10371.

29 Hayes NL, Nowakowski RS. Exploiting the dynamics of S-phase tracers in developing brain: interkinetic nuclear migration for cells entering versus leaving the S-phase. Dev Neurosci 2000; 22: 44-55.

30 Peffer ME, Chandran UR, Luthra S, Volonte D, Galbiati F, Garabedian MJ et al. Caveolin-1 regulates genomic action of the glucocorticoid receptor in neural stem cells. Mol Cell Biol 2014; 34: 2611-2623.

31 Arai Y, Pulvers JN, Haffner C, Schilling B, Nusslein I, Calegari F et al. Neural stem and progenitor cells shorten S-phase on commitment to neuron production. Nat Commun 2011; 2: 154

32 Sun T, Hevner RF. Growth and folding of the mammalian cerebral cortex: from molecules to malformations. Nat Rev Neurosci 2014; 15: 217-232.

33 Hsu SC, Qi M, DeFranco DB. Cell cycle regulation of glucocorticoid receptor function. $E M B O$ J 1992; 11: 3457-3468.
34 Packard DS Jr, Menzies RA, Skalko RG. Incorportaiton of thymidine and its analogue, bromodeoxyuridine, into embryos and maternal tissues of the mouse. Differentiation 1973; 1: 397-404.

35 Samarasinghe RA, Di Maio R, Volonte D, Galbiati F, Lewis M, Romero G et al. Nongenomic glucocorticoid receptor action regulates gap junction intercellular communication and neural progenitor cell proliferation. Proc Natl Acad Sci USA 2011; 108: 16657-16662.

36 Meijer OC, de Lange EC, Breimer DD, de Boer AG, Workel JO, de Kloet ER. Penetration of dexamethasone into brain glucocorticoid targets is enhanced in mdr1A P-glycoprotein knockout mice. Endocrinology 1998; 139: 1789-1793.

37 Frahm KA, Peffer ME, Zhang JY, Luthra S, Chakka AB, Couger MB et al. Research resource: the dexamethasone transcriptome in hypothalamic embryonic neural stem cells. Mol Endocrinol 2016; 30: 144-154.

38 Cheung M, Pei J, Pei Y, Jhanwar SC, Pass HI, Testa JR. The promyelocytic leukemia zinc-finger gene, PLZF, is frequently downregulated in malignant mesothelioma cells and contributes to cell survival. Oncogene 2010; 29: 1633-1640.

39 Taylor V, Welcher AA, Program AE, Suter U. Epithelial membrane protein-1, peripheral myelin protein 22, and lens membrane protein 20 define a novel gene family. J Biol Chem 1995; 270: 28824-28833.

40 Porsolt RD, Bertin A, Jalfre M. Behavioral despair in mice: a primary screening test for antidepressants. Arch Int Pharmacodyn Ther 1977; 229: 327-336.

41 Surbek D, Drack G, Irion O, Nelle M, Huang D, Hoesli I. Antenatal corticosteroids for fetal lung maturation in threatened preterm delivery: indications and administration. Arch Gynecol Obstet 2012; 286: 277-281.

42 Huang CC, Lin HR, Liang YC, Hsu KS. Effects of neonatal corticosteroid treatment on hippocampal synaptic function. Pediatr Res 2007; 62: 267-270.

43 Slotkin TA, Barnes GA, McCook EC, Seidler FJ. Programming of brainstem serotonin transporter development by prenatal glucocorticoids. Brain Res Dev Brain Res 1996; 93: 155-161.

44 Slotkin TA, Kreider ML, Tate CA, Seidler FJ. Critical prenatal and postnatal periods for persistent effects of dexamethasone on serotonergic and dopaminergic systems. Neuropsychopharmacology 2006; 31: 904-911.

45 Kreider ML, Tate CA, Cousins MM, Oliver CA, Seidler FJ, Slotkin TA. Lasting effects of developmental dexamethasone treatment on neural cell number and size, synaptic activity, and cell signaling: critical periods of vulnerability, dose-effect relationships, regional targets, and sex selectivity. Neuropsychopharmacology 2006; 31: 12-35.

46 Huang L-T. The link between perinatal glucocorticoids exposure and psychiatric disorders. Pediatr Res 2011; 69 (5, Part 2 of 2) 19R-25R.

47 Kriegstein A, Noctor S, Martinez-Cerdeno V. Patterns of neural stem and progenitor cell division may underlie evolutionary cortical expansion. Nat Rev Neurosci 2006; 7: 883-890.

48 Hansen DV, Lui JH, Parker PR, Kriegstein AR. Neurogenic radial glia in the outer subventricular zone of human neocortex. Nature 2010; 464: 554-561.

49 Carlos RQ, Seidler FJ, Slotkin TA. Fetal dexamethasone exposure alters macromolecular characteristics of rat brain development: a critical period for regionally selective alterations? Teratology 1992; 46: 45-59.

50 Khozhai LI, Otellin VA. Formation of neocortex and hippocampus structures after single action of dexamethasone at prenatal period of rat development. Zh Evol Biokhim Fiziol 2008; 44: 446-448.

51 Chen XK, Lougheed J, Lawson ML, Gibb W, Walker RC, Wen SW et al. Effects of repeated courses of antenatal corticosteroids on somatic development in children 6 to 10 years of age. Am J Perinatol 2008; 25: 21-28.

52 Bustamante C, Bilbao P, Contreras W, Martinez M, Mendoza A, Reyes A et al. Effects of prenatal stress and exercise on dentate granule cells maturation and spatial memory in adolescent mice. Int J Dev Neurosci 2010; 28: 605-609.

53 Lemaire V, Koehl M, Le Moal M, Abrous DN. Prenatal stress produces learning deficits associated with an inhibition of neurogenesis in the hippocampus. Proc Natl Acad Sci USA 2000; 97: 11032-11037.

54 Aghajafari F, Murphy K, Matthews S, Ohlsson A, Amankwah K, Hannah M. Repeated doses of antenatal corticosteroids in animals: a systematic review. Am J Obstet Gynecol 2002; 186: 843-849.

55 Aghajafari F, Murphy K, Ohlsson A, Amankwah K, Matthews S, Hannah ME. Multiple versus single courses of antenatal corticosteroids for preterm birth: a pilot study. J Obstet Gynaecol Can 2002; 24: 321-329.

56 Lupien SJ. Brains under stress. Can J Psychiatry 2009; 54: 4-5.

57 Lupien SJ, McEwen BS, Gunnar MR, Heim C. Effects of stress throughout the lifespan on the brain, behaviour and cognition. Nat Rev Neurosci 2009; 10: 434-445.

58 Harris A, Seckl J. Glucocorticoids, prenatal stress and the programming of disease. Horm Behav 2011; 59: 279-289.

59 Waffarn F, Davis EP. Effects of antenatal corticosteroids on the hypothalamicpituitary-adrenocortical axis of the fetus and newborn: experimental findings and clinical considerations. Am J Obstet Gynecol 2012; 207: 446-454.

60 Abraham IM, Harkany T, Horvath KM, Luiten PG. Action of glucocorticoids on survival of nerve cells: promoting neurodegeneration or neuroprotection? J Neuroendocrinol 2001; 13: 749-760. 
61 Alfarez DN, De Simoni A, Velzing EH, Bracey E, Joels M, Edwards FA et al. Corticosterone reduces dendritic complexity in developing hippocampal CA1 neurons. Hippocampus 2009; 19: 828-836.

62 Arango-Lievano M, Lambert WM, Bath KG, Garabedian MJ, Chao MV, Jeanneteau F. Neurotrophic-priming of glucocorticoid receptor signaling is essential for neuronal plasticity to stress and antidepressant treatment. Proc Natl Acad Sci USA 2015; 112: 15737-15742.

63 Muller MB, Zimmermann S, Sillaber I, Hagemeyer TP, Deussing JM, Timpl P et al. Limbic corticotropin-releasing hormone receptor 1 mediates anxiety-related behavior and hormonal adaptation to stress. Nat Neurosci 2003; 6: 1100-1107.
This work is licensed under a Creative Commons Attributioncc) NonCommercial-NoDerivs 4.0 International License. The images or
other third party material in this article are included in the article's Creative Commons license, unless indicated otherwise in the credit line; if the material is not included under the Creative Commons license, users will need to obtain permission from the license holder to reproduce the material. To view a copy of this license, visit http:// creativecommons.org/licenses/by-nc-nd/4.0/

(c) The Author(s) 2017

Supplementary Information accompanies the paper on the Translational Psychiatry website (http://www.nature.com/tp). 